Atrkivoc

Free to Authors and Readers
A Platinum Open Access Journal

for Organic Chemistry
Account

Arkivoc 2021, part i, 20-47

\title{
Atropisomerism as inspiration for new chemistry
}

Mariel M. Cardenas, Ashley D. Nguyen, Zachary E. Brown, Beeta S. Heydari, Bahar S. Heydari, Sagar D. Vaidya, and Jeffrey L. Gustafson*

Department of Chemistry and Biochemistry, San Diego State University, 5500 Campanile Drive, San Diego, California 92182, United States

Email:jgustafson@sdsu.edu

Received 09-23-2020

Accepted 11-11-2020

Published on line 01-05-2021

\section{Abstract}

Atropisomerism is a type of chirality that is ubiquitous but often overlooked in modern drug discovery. In this Account we discuss studies on leveraging atropisomerism as a design principle in medicinal chemistry, and how this work led to several seemingly disparate projects that began due to synthetic challenges associated with accessing pharmaceutically relevant atropisomers.

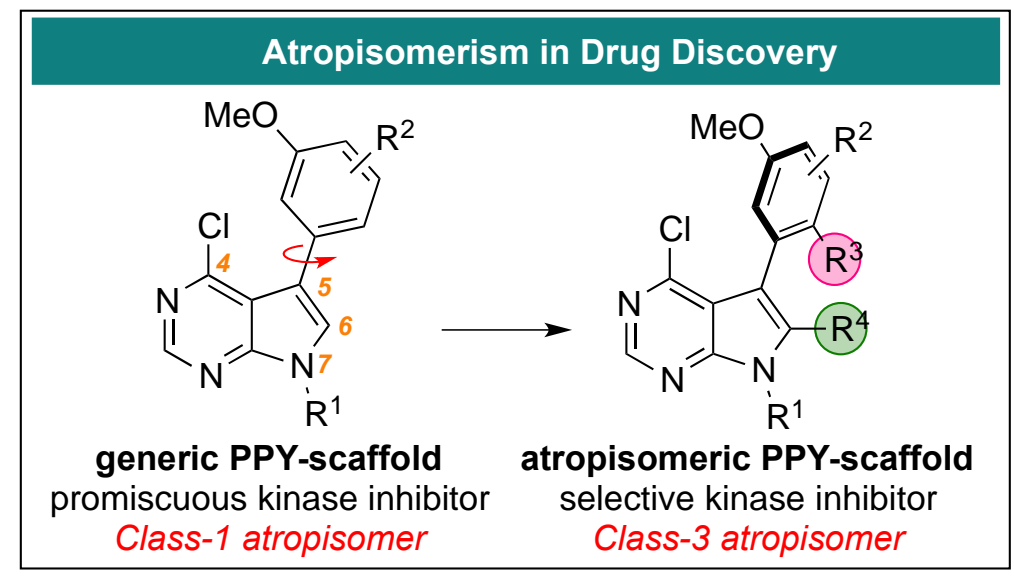

Can we access pharmaceutically relevant atropisomers?

- Lewis base catalyzed halogenation ( $\left.S_{E} A r\right)$

- Regioselective syntheses

- Atroposelective Catalysis

Keywords: Atropisomer; medicinal chemistry; regioselective; $\mathrm{S}_{\mathrm{E}} \mathrm{Ar}$; atroposelective catalysis 


\section{Table of Contents}

1. Introduction

2. Developing Lewis Base Catalysis as a Method for the Late-Stage Functionalization of Pharmaceutically Relevant Scaffolds

2.1. Developing a Lewis base catalyzed $\mathrm{S}_{\mathrm{E}} \mathrm{Ar}$ strategy

2.2. The regioselective chlorination of phenols

2.3. Lewis base catalyzed radical bromination

2.4. Lewis base/Brønsted acid dual catalyzed sulfenylation of aromatics

2.5. Photocatalytic ' $\mathrm{C}-\mathrm{H}$ ' sulfenylation of aromatics

3. Modulating the Potency and Selectivity of Kinase Inhibitors Through the Introduction of Class-3 Atropisomerism

4. Developing Atroposelective Synthetic Methods Towards Pharmaceutically Relevant Scaffolds

4.1. Atroposelective nucleophilic aromatic substitution $\left(S_{N} A r\right)$ strategies towards 3-aryl PPYs

4.2. Atroposelective vicarious nucleophilic substitution (VNS)-like strategies towards atropisomeric naphthoquinones

4.3. Atroposelective Lewis acid catalyzed halogenation towards atropisomeric $N$-aryl quinoids

5. Conclusion

References

\section{Introduction}

(a)

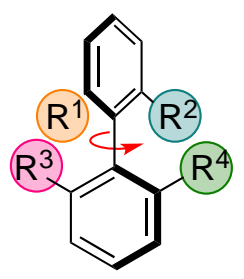

(b)

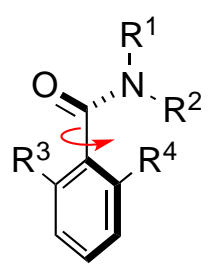

benzamides

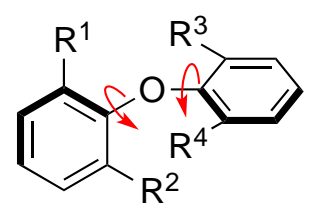

diaryl ethers

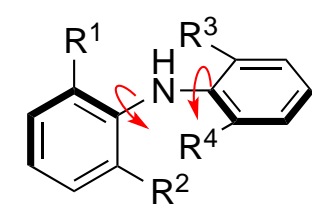

diaryl amines

(c)<smiles>Oc1ccc2ccccc2c1-c1c(O)ccc2ccccc12</smiles>

$\left(R_{\mathrm{a}}\right)$-BINOL<smiles>Oc1ccc2ccccc2c1-c1c(O)ccc2ccccc12</smiles>

$\left(S_{\mathrm{a}}\right)$-BINOL

Figure 1. a) Atropisomer racemization occurs via bond rotation (red arrow); stereochemical stability of atropisomers are denoted as barrier to rotation $\left(\Delta G_{r a c}\right) ; R^{1} \neq R^{2} \neq R^{3} \neq R^{4}$. b) Examples of potentially stable, nonbiaryl atropisomers. c) Example of stable, biaryl atropisomer BINOL. Both atropisomers are shown.

Atropisomerism is a stereochemical phenomenon that occurs when there is a hindered rotation about an axis, most commonly seen in the context of a $\sigma$-bond between two $\mathrm{sp}^{2}-\mathrm{sp}^{2}$ atoms (Figure 1a). While atropisomerism is typically exemplified by the biaryl scaffold, axial chirality can be observed in diverse structural motifs including benzamides, diaryl ethers, diaryl amines, anilides, and $\mathrm{N}-\mathrm{C}$ aryl atropisomeric 
scaffolds (Figure 1b). ${ }^{1-7}$ Atropisomerism is different from other forms of chirality as $\sigma$-bond rotation leads to a spontaneous mechanism of racemization. As such, atropisomers can span the gamut of stereochemical stability from rapidly interconverting atropisomers that racemize on less than the second time scale to highly

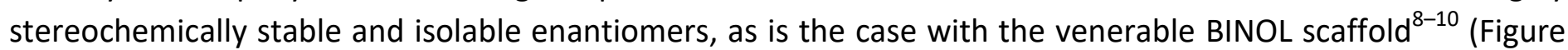
1c) and countless natural products. ${ }^{11}$

While traditionally a scaffold is considered to be atropisomeric only if its half-life to racemization $\left(t_{1 / 2}\right)$ is $>1000$ seconds at room temperature, LaPlante and colleagues ${ }^{12}$ have put forward a more sophisticated system where they group atropisomers into three classes. Class-3 atropisomers possess barriers to rotation $\left(\Delta \mathrm{G}_{\mathrm{rac}}\right)$ above $30 \mathrm{kcal} / \mathrm{mol}$ and are considered stereochemically stable in the context of drug discovery, with $t_{1 / 2}$ to racemization at room temperature on the year or greater time scale. Class- 2 atropisomers possess stereochemical stabilities that are considered 'meta-stable' in that the atropisomers can be isolated in enantiopure form, however, racemization will occur on the day to month timescale at room temperature. Finally, Class-1 atropisomers encompass all atropisomeric scaffolds wherein the enantiomers cannot be isolated due to rapid racemization at room temperature (Figure 2). ${ }^{13-15}$

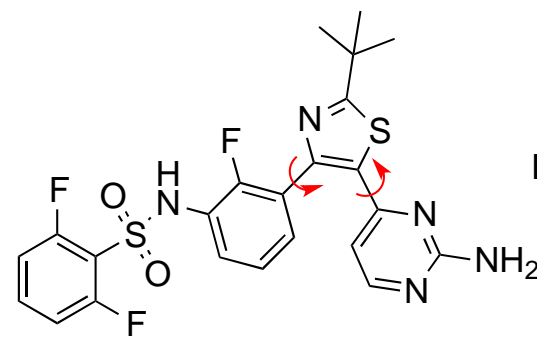

Class-1 Atropisomer Dabrafenib, FDA approved BRAF inhibitor (chemotherapeutic)

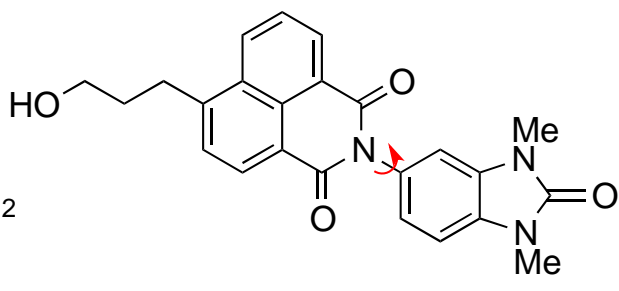

Class-2 Atropisomer Bayer Bromodomain Chemical Probe

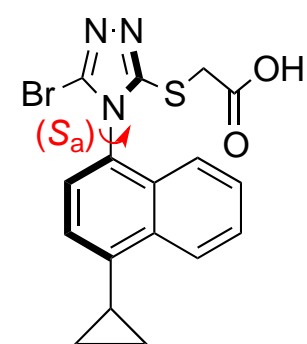

Class-3 Atropisomer

Lesinurad, FDA approved urate transport inhibitor

$$
\begin{aligned}
& \text { Class-1 } \\
& t_{1 / 2} \sim \sec \\
& \text { Class-2 } \\
& t_{1 / 2} \sim \text { day (lower end) } \\
& t_{1 / 2} \sim \text { month (higher end) }
\end{aligned}
$$

$10 \mathrm{kcal} / \mathrm{mol}$

$20 \mathrm{kcal} / \mathrm{mol}$

$30 \mathrm{kcal} / \mathrm{mol}$

$40 \mathrm{kcal} / \mathrm{mol}$

Figure 2. Examples of atropisomerism in drug discovery overlaid with the ranges of each class of atropisomer stability.

We were inspired by Class-1 atropisomers, as they proved to be prevalent throughout modern drug discovery. Indeed, our group has recently published an analysis ${ }^{1}$ wherein we found that almost a third of small molecule drugs that were approved by the FDA since 2011 possessed at least one Class-1 axis of atropisomerism. Atropisomerism was even more represented in some classes of drugs. For example, close to $85 \%$ of kinase inhibitors possess at least one instance of Class-1 atropisomerism. While many of these Class-1 atropisomers are thought to be 'flat' planar compounds, analysis of crystallographic data demonstrates class-1 atropisomers bind a given protein target in an atropisomer selective fashion.

Analysis of such crystallographic data in the PDB led us to hypothesize that preorganizing a Class-1 atropisomeric axis to the preferred atropisomeric configuration of a given target can have significant effects on the target selectivity of the scaffold by precluding other conformations that might bind to other targets and thus contribute off-target activities. This hypothesis has been a central tenet of our work, and pursuit of the syntheses of compounds to test this hypothesis has necessitated us to undertake seemingly unrelated 
research directions. For example, early on we had to develop new methodologies that allowed for the mild and regioselective functionalization of pharmaceutically relevant scaffolds that could be used to rigidify Class1 axes to Class-3 axes (Section 2). With this chemistry in hand, we were able to study the effect of atropisomerism on the potency and selectivity of promiscuous kinase inhibitors, learning that both atropisomeric conformation and accessible conformations about the axis played a key role (Section 3). Finally, our work on the effects of atropisomerism on the biological activity of small molecules led us to realize that there was a need for more efficient access to enantiopure samples leading us to work on several projects concerning diverse chemical strategies towards the atroposelective synthesis of pharmaceutically relevant atropisomeric scaffolds including biaryls, heterobiaryls, diaryl ethers, diaryl amines, and related scaffolds (Section 4). As each project has been instrumental towards carrying out other projects, we have fashioned this account to cover our work in detail, and hopefully demonstrate their interconnectedness.

\section{Developing Lewis Base Catalysis as a Method for the Late-Stage Functionalization of Pharmaceutically Relevant Scaffolds}

\subsection{Developing a Lewis base catalyzed $\mathrm{S}_{\mathrm{E}} \mathrm{Ar}$ strategy}

Halogenation of arenes and heterocycles are commonly achieved using electrophilic aromatic substitution $\left(S_{E} A r\right)$, however there are a lack of mild methodologies to perform $S_{E} A r$ on more complex substrates, and more generally $\mathrm{S}_{\mathrm{E}} \mathrm{Ar}$ is largely an unsolved problem for the late-stage functionalization of complex molecules. ${ }^{16}$ We were interested in the direct regioselective chlorination of pyrrolopyrimidines (PPYs), a common kinase inhibitor scaffold, as it represented an efficient synthetic strategy to obtain Class-3 atropisomeric analogues. Evaluation of several common conditions resulted in no conversions or complex mixtures of products, leading us to turn our attention to developing a more reactive yet mild strategy towards the electrophilic halogenation of aromatics (Scheme 1a).

We were initially inspired by the work of Denmark on the Lewis base catalyst activation of $N$ halosuccinimides for the electrophilic functionalization of alkenes. ${ }^{17}$ In this work, they observed that Lewis bases could activate NXS and influence the rate and constitutional site selectivity of halolactonizations. The use of catalytic amounts of common Lewis bases such as thioureas, phosphine sulfides, and thiophosphoramides resulted in increased reaction rates and good yields (up to 90\%) of cyclized product. Furthermore, the structure of the Lewis base seemed to have an effect on the regioselectivity of the reaction. The observed influence on the constitutional site preference of the product suggested that the Lewis base is involved in the transitional structure.

Based on these results, we hypothesized that electrophiles could be activated by Lewis bases to effect $S_{E} A r$. Indeed, we found that phosphine sulfides, such as triphenylphosphine sulfide 1 or tributylphosphinesulfide (2), are able to catalyze the halogenation of diverse aromatics (Scheme 1b) through activation of readily available $N$-halosuccinimide reagents $N X S(X=C l, B r, I) .{ }^{18}$ It is worth noting that more electron rich phosphine sulfides such as $\mathbf{2}$ were more active catalysts, however catalyst $\mathbf{1}$ was chosen as the featured catalyst as it is commercially available, inexpensive, and still furnished significant reaction rate accelerations compared to the absence of catalyst. This chemistry proved amenable to diverse heterocycles including azaindoles (i.e. 3), pyrrolopyrimidines (i.e. PPYs, 4), and various arenes (i.e. 5). Furthermore, 1 also resulted in marked improvements for electrophilic aromatic bromination (i.e. 6) and iodination (i.e. 7). For the majority of substrates, no reaction was observed in the absence of catalyst and the catalyzed reaction rate compared favorably to the state-of-the-art conditions of Baran's chloro-bis(methoxycarbonyl)guanidine (CBMG) reagent. ${ }^{19}$ 
(a)

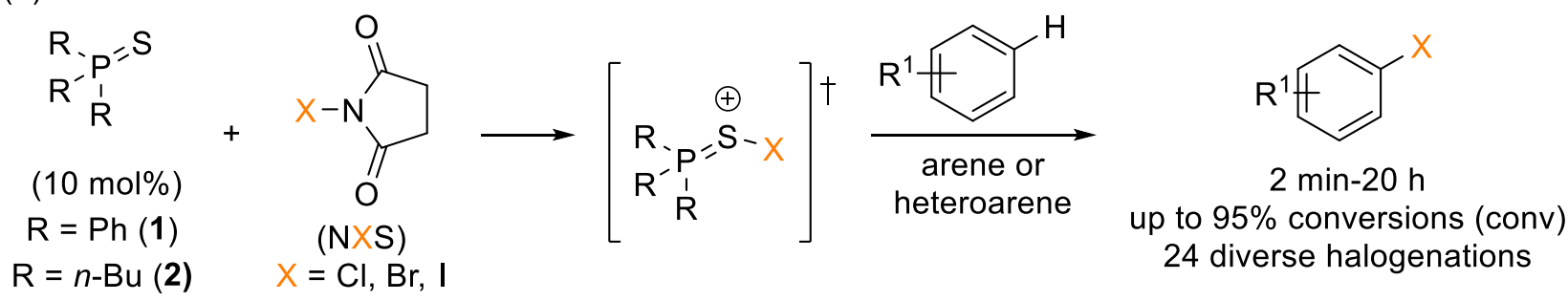

(b)

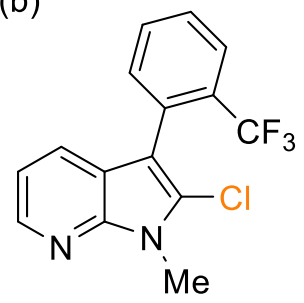

3

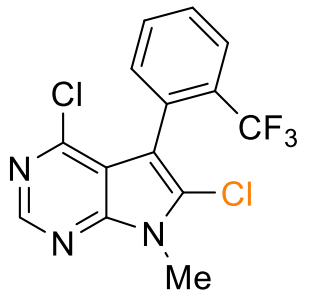

4

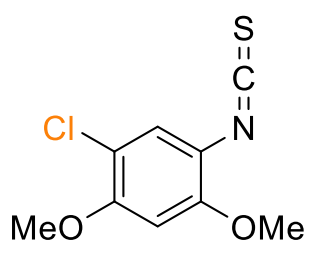

5

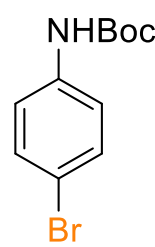

6<smiles>Cn1cc(I)c2c(Cl)ncnc21</smiles>

7

No cat: 18 h, $0 \%$ conv No cat: 2 h, $0 \%$ conv No cat: 1 h, $0 \%$ conv No cat: 5 min, $0 \%$ conv No cat: 0.5 h, $0 \%$ conv

1: $18 \mathrm{~h}, 84 \%$ conv

2: 12 h, $94 \%$ conv

1: $18 \mathrm{~h}, 92 \%$ conv

1: $1 \mathrm{~h}, 91 \%$ conv

1: $15 \mathrm{~min}, 86 \%$ conv

1: $0.5 \mathrm{~h}, 81 \%$ conv

2: $22 \mathrm{~min}, 92 \%$ conv

Scheme 1. (a) The Lewis base catalyzed electrophilic halogenation of pharmaceutically relevant arenes and heterocycles. (b) Illustrative examples of substrate scope.

\subsection{The regioselective chlorination of phenols}

We performed several DFT calculations on the phosphine sulfide-NXS system, and in line with work by Denmark $^{17}$ these studies suggested the chemistry proceeded via a direct Lewis base-halenium adduct. Fascinated by this observation, we wanted to explore whether the structure of the Lewis basic catalyst could control the regiochemical outcome of halogenation. Controlling the regioselective outcome of $S_{E} A r$ on aromatics and heteroaromatics is a largely unsolved problem as many aromatics have multiple reactive sites. ${ }^{20}$ Current methods that halogenate one constitutional isomer rely on substrate modifications such as blocking the position of unwanted halogenation, or require the use of harsh conditions. ${ }^{21,22}$ These methodologies cannot be applied for the use in late-stage functionalization (LSF) of pharmaceutically relevant scaffolds as they can irreversibly alter the substrate structure or are not functional group tolerant. ${ }^{23}$ There is an unmet need to develop a method that relies on catalyst control to overcome a substrate's innate regioselectivity.

From an energetic perspective, obtaining catalyst controlled regioselectivity can be more challenging than obtaining enantioselectivity (Figure 3). In enantioselective catalysis, the enantiodivergent pathways have transition states that are equal in energy, meaning a catalyst needs to only prefer one pathway by $\sim 1.3$ $\mathrm{kcal} / \mathrm{mol}$ to yield a 9:1 enantiomeric ratio. On the other hand, in a regioselective reaction the regiodivergent reaction pathways possess transition states that are at different energy levels. Therefore, in many cases a catalyst must first initially overcome the innate selectivity of the reaction plus an additional $\sim 1.3 \mathrm{kcal} / \mathrm{mol}$ to achieve a 9:1 ratio of constitutional isomers (figure 3). ${ }^{24}$ Currently there are only few examples in the literature of catalyst controlled regioselective additions in the context of $S_{E} A r,{ }^{25,26}$ including seminal work by Miller selectively brominating complex natural products using a peptide-based catalyst. ${ }^{27} \mathrm{~A}$ regiodivergent approach was pioneered by Lewis using enzymes evolved from RebH to chlorinate indoles and other arenes with stunning site-selectivities. ${ }^{28,29}$ 


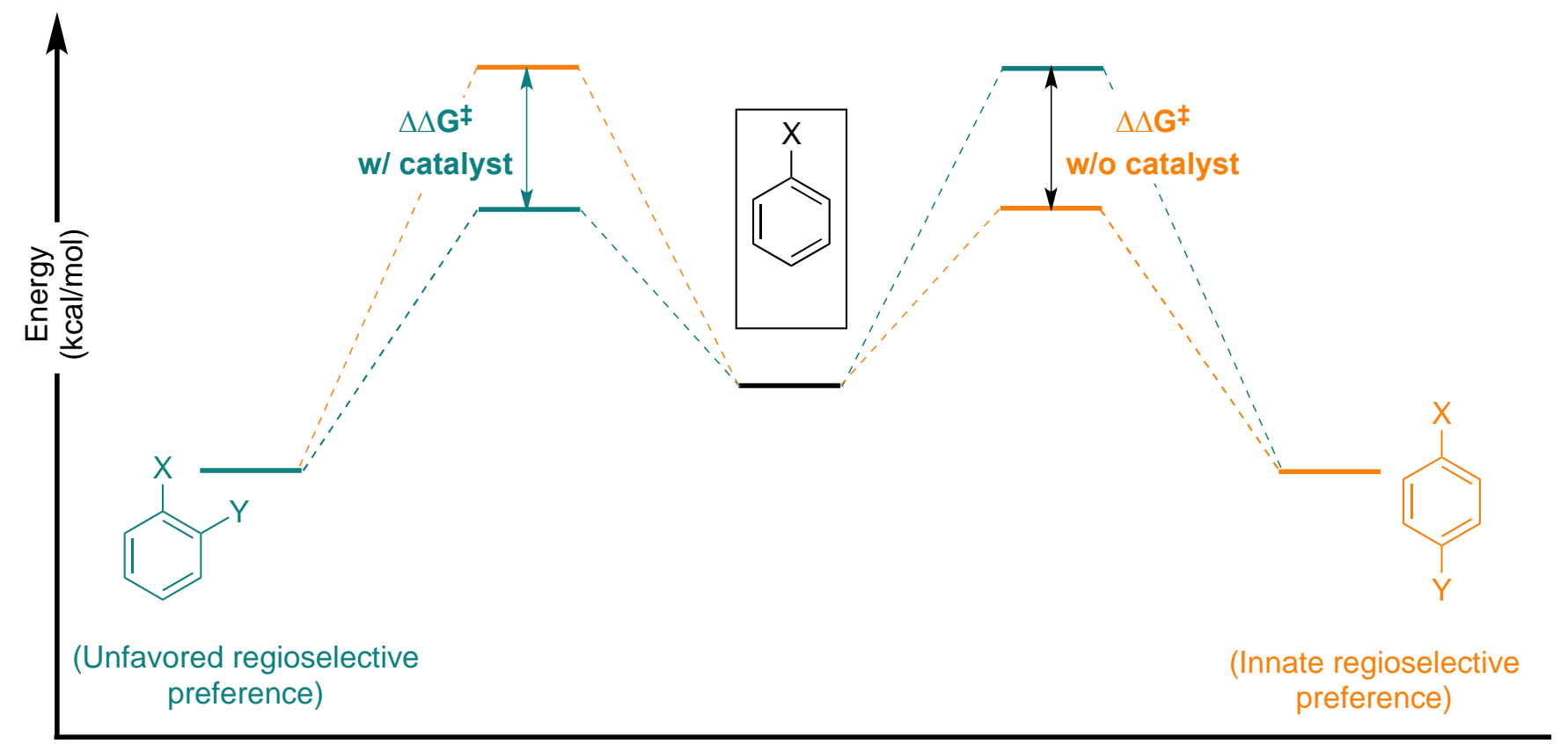

Catalyst controlled regioselective preference $\quad \square$ Innate regioselective preference

Figure 3. Challenge of regioselectivity: innate vs. catalyst-controlled $\mathrm{S}_{\mathrm{E}} \mathrm{Ar}$ of arenes

(a)<smiles>[R][R]1cccc(O)c1</smiles>

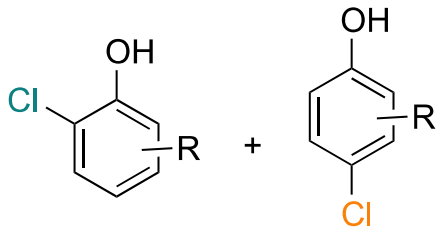

\begin{tabular}{|c|c|}
\hline Catalyst & $\begin{array}{c}\text { \# of examples, } \\
\text { ortho }(\mathrm{o}): \text { para }(\mathrm{p})\end{array}$ \\
\hline $\mathbf{8}$ & 10 examples, up to $16: 1$ o:p \\
$\mathbf{9}$ & 10 examples, up to $1: 20$ o:p \\
\hline
\end{tabular}

(b)<smiles>Nc1cc(C(F)(F)F)cc(C(F)(F)F)c1</smiles><smiles>NC(=S)N[C@H]1CCCC[C@@H]1NC(=S)Nc1cc(C(F)(F)F)cc(C(F)(F)F)c1</smiles>

catalyst 8

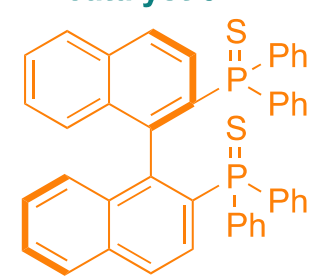

catalyst 9<smiles>Oc1c(Cl)cccc1-c1ccccc1</smiles>

10

$75 \%$ yield 10:1 o:p<smiles>Oc1ccc(Cl)cc1-c1ccccc1</smiles>

13

$89 \%$ yield 1:12 o:p<smiles>Oc1c(Cl)cccc1I</smiles>

11 $65 \%$ yield 8:1 o:p<smiles>Oc1ccc(Cl)cc1I</smiles>

14

$86 \%$ yield 1:20 o:p<smiles>Oc1c(F)cccc1Cl</smiles>

12 $73 \%$ yield 16:1 o:p<smiles>Oc1ccc(Cl)cc1Br</smiles>

15 $72 \%$ yield 1:6 o:p (a)

(c) Proposed model for ortho-Cl of phenol

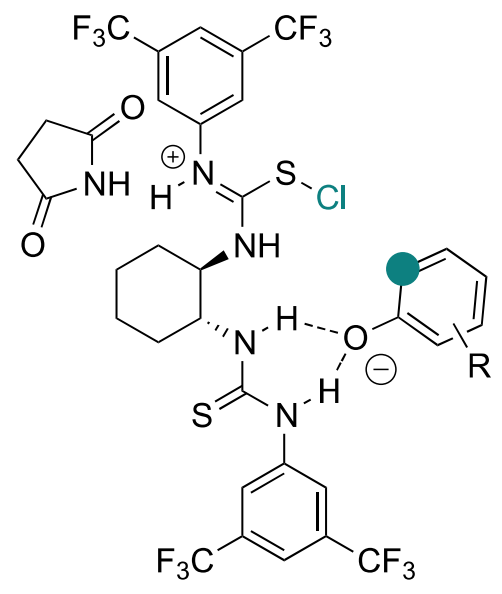

Scheme 2. (a) General scheme for regiodivergent chlorination. (b) Selected substrates affected by ortho- and para- selective catalysts. (c) Proposed model of regioinduction by catalyst $\mathbf{8}$.

Intrigued by this challenge, we set out to determine if Lewis basic catalysts could control the regioselectivity of $S_{E} A r$, initially focusing on phenols which typically yield an innate preference of $\sim 4: 1$ favoring 
para $\mathrm{S}_{\mathrm{E}} \mathrm{Ar}$ (Scheme 2a). After evaluating several Lewis base catalysts, we found that Nagasawa's bisthiourea catalyst $^{30} \mathbf{8}$ was able to overcome the innate para-selectivity of $S_{E} A r$ on phenols, yielding up to 20:1 ortho to para ratios. For comparison, catalyst 1 yielded a 1:3 ortho:para ratio. These ortho-selectivities held across a range of substituted phenols (Scheme $2 \mathrm{~b}$ ) to give ortho chlorinated phenols such as 10,11, and 12 . We hypothesize that the regio-control of Nagasawa's catalyst 8 proceeds via a mechanism in which one thiourea moiety is interacting with the hydroxyl group of phenol, and the other one activates NCS through a Lewis basic mechanism (Scheme 2c). ${ }^{31}$ We also found that bis(diphenylphosphino)-1,1'-binapthyl(BINAP)-derived phosphine sulfide 9 routinely yielded improved para-selectivities compared to catalyst 1, with 9 often resulting in ortho:para ratios of more than 1:15 ${ }^{32}$ The improved para selectivity of 9 was recently leveraged by Takahashi in the total synthesis of the kehokorins. ${ }^{33}$

\subsection{Lewis base catalyzed radical bromination}

(a)

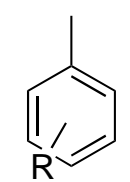

$$
\mathrm{SePPh}_{3}(\mathbf{1 6}, 10 \mathrm{~mol} \%)
$$$$
\underset{\mathrm{CDCl}_{3}, 2-5 \mathrm{~h}}{\stackrel{\mathrm{NBS}}{\longrightarrow}}
$$

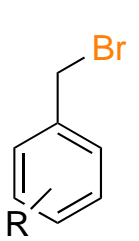

7 examples up to $89 \%$ yield

(c)

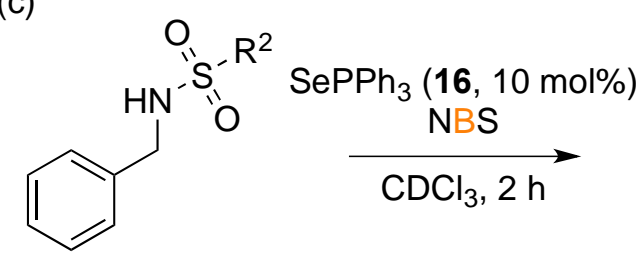

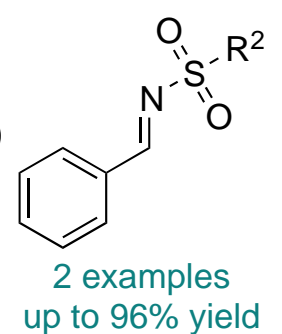

(b)

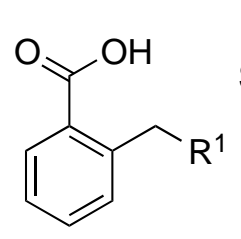

$\mathrm{SePPh}_{3}(\mathbf{1 6}, 10 \mathrm{~mol} \%)$ NBS $\mathrm{CDCl}_{3}, 2 \mathrm{~h}$<smiles>[R]C1CCc2ccccc21</smiles>

3 examples up to $70 \%$ yield (d)

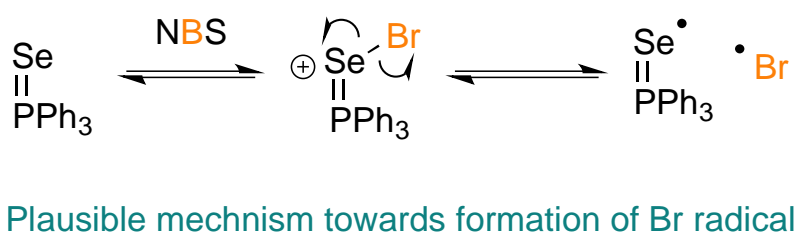

Scheme 3. (a) Benzylic bromination catalyzed by phosphine selenides. (b) Synthesis of phthalate lactones via benzylic bromination followed by intermolecular $S_{N} 2$. (c) Imine formation via selenide catalyzed benzylic bromination. (d) Proposed mechanistic model for formation of bromine radical.

When evaluating catalyst 1 and other Lewis bases for bromination of alkyl substituted arenes, we observed trace amounts of benzylic bromination. This was in line with observations from Mukherjee ${ }^{34}$ and Tunge $^{35}$ wherein they found that thioureas or selenides can affect radical bromination reactions. Intrigued by their work we hypothesized that the nature of the Lewis base could be tuned to prefer radical halogenation reactions over $S_{E} A r$. Evaluation of different Lewis bases led us to find that simply switching the sulfur in 1 to selenium in 16 led to efficient benzylic bromination using NBS. ${ }^{36}$ For example, the addition of 10 mol\% of triphenylphosphine selenide $\mathbf{1 6}$ afforded 89\% yield of benzyl bromide from toluene. This methodology was applied to several substrates, typically resulting in clean benzylic bromination (Scheme 3a). The utility of this methodology was demonstrated on substrates that can be reacted further upon bromination. For example, we were able to synthesize phthalate lactones ${ }^{37}$ from substituted benzoic acid derivatives (Scheme $3 b$ ) and imines from benzylsulfonylamines (Scheme $3 c$ ). We then studied this reaction computationally, finding that this chemistry likely proceeded via a Lewis base halenium adduct that would then homolytically cleave to give 
bromine radical due to the lower oxidation potential of selenium compared to sulfur (Scheme $3 \mathrm{~d}$ ). $\mathrm{The} \mathrm{Br}$ radical would then undergo benzylic bromination via the canonical Wohl-Ziegler mechanism. ${ }^{38}$

\subsection{Lewis base/Brønsted acid dual catalyzed sulfenylation of aromatics}

Aryl sulfides are common functionalities and synthetic intermediates in drug discovery ${ }^{39-41}$ and material science. ${ }^{42}$ For example, the kinase inhibitor Axitinib is an FDA-approved diaryl sulfide. ${ }^{43-45}$ Typically, C-S bonds are created through cross-couplings via metal catalysis, ${ }^{46-48}$ but this generally requires the use of prefunctionalized starting materials and transition metal catalysts. Sulfenylation via $S_{E} A r$ is an emerging strategy for aromatic C-S bond formation, with the majority of examples utilizing electrophilic $N$-thiosuccinimides. ${ }^{49-51}$ While seminal, these examples suffer from limited substrate scope or a reliance on super-stoichiometric quantities of strong acids.

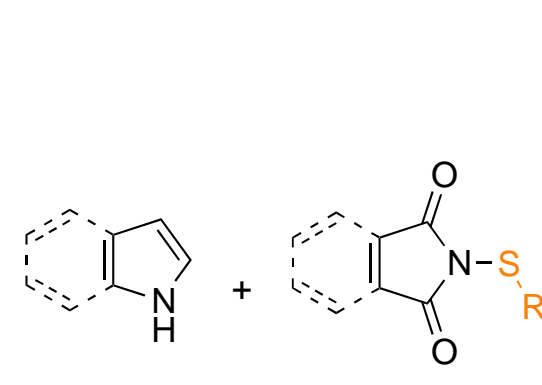

(various heterocycles, e.g. indole)

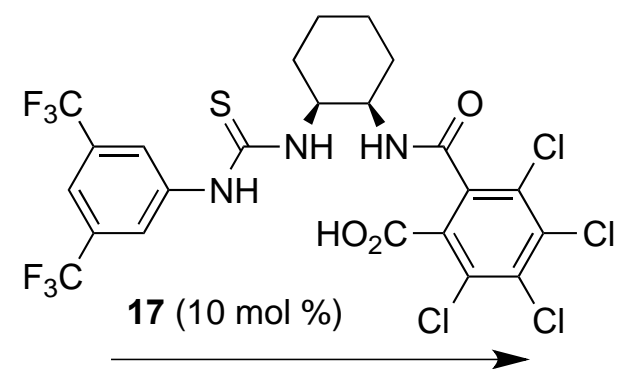

$\mathrm{CH}_{2} \mathrm{Cl}_{2}(0.2 \mathrm{M})$

r.t., up to $48 \mathrm{~h}$

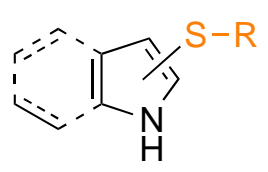

19 examples

(including various peptides and pharamceuticals)

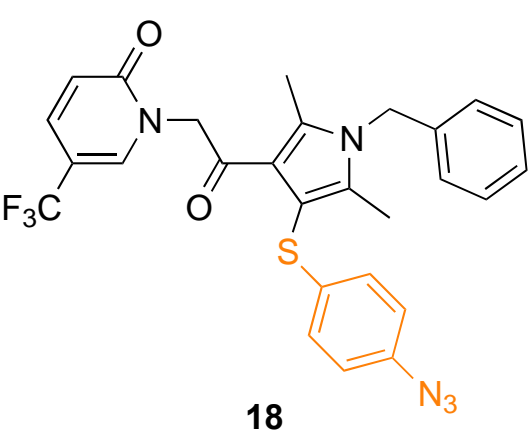

$48 \mathrm{~h}, 62 \%$ yield

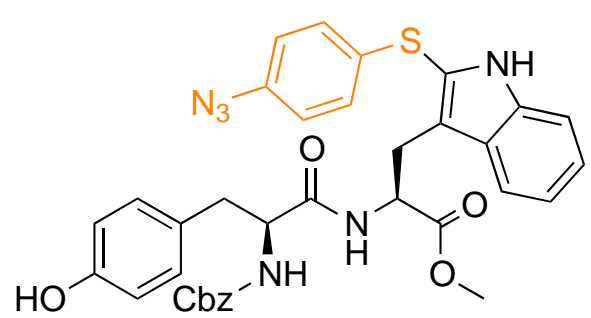

19

$4 \mathrm{~h}, 96 \%$ yield

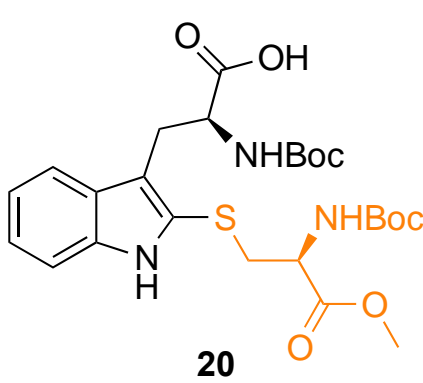

$18 \mathrm{~h}, 58 \%$ yield

Scheme 4. Lewis base-Brønsted acid catalyzed sulfenylation of nitrogen containing heterocycles

As we have previously demonstrated that catalytic amounts of Lewis bases can activate $N$ halosuccinimides for $S_{E} A r$, we hypothesized that Lewis bases could also activate $N$-thiosuccinimides in a similar vein. $^{52}$ We quickly found that while Lewis bases could not effect aromatic sulfenylation alone, they could in the presence of catalytic amounts of Brønsted acid. While promising, we wanted to achieve more mild and simplified reaction conditions, thus we sought out to create a bifunctional catalyst that contained both Lewis base and Brønsted acid moieties. We initially evaluated thioureas derived from diamines, finding that pendant carboxylic acids led to promising results. After synthesizing a small library of catalysts with varying rigidities and distances between the Lewis basic thiourea and a Brønsted acid, we found catalyst 17 to be optimal, allowing for the sulfenylation of diverse pyrroles and indoles under mild conditions (Scheme 4). Of note, this chemistry was applicable to the incorporation of diverse sulfide moieties, including functional groups such as azides as in $\mathbf{1 8}$ and $\mathbf{1 9}$, amino acids as in 20, and medicinally useful groups such as the trifluoromethylthio 
group $\left(\mathrm{SCF}_{3}\right)$. While our goal was to avoid the use of strong acids, it is important to mention that we saw full conversion on the minute time scale upon addition of TFA to catalyst 17.

We next set out to improve the substrate scope of Lewis base catalyzed sulfenylation to include less electron rich arenes. ${ }^{53}$ Inspired by the work of Zhao, ${ }^{54,55}$ we evaluated a series of chalcogenide ethers, finding that catalytic amounts of electron rich selenoether catalysts $\mathbf{2 1}$ are the effective arene sulfenylation catalysts in the presence of 10 mol\% trifluoromethanesulfonic acid (TfOH). During optimization we observed that electron rich sulfide products underwent a competing autocatalytic sulfenylation, and thus did not need added Lewis base catalyst (Scheme 5). On the other hand, electron poor sulfide products (i.e. products wherein the trifuoromethylthio-group was added) did not undergo autocatalysis, thus added selenoether catalyst was necessary. Overall, this system allowed for the incorporation of electron poor sulfides into diverse arenes (Scheme 5). For example, we were able to directly incorporate an azide into the FDA-approved drug Naproxen to give 22, as well as a trifluoromethylthio group into pharmaceuticals Tolmetin to give $\mathbf{2 3}$ and Paroxetine to give 24.

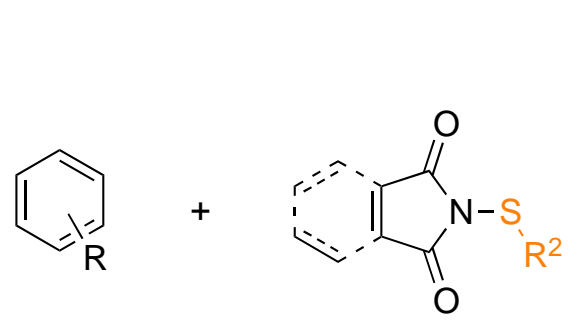

(arene or heterocycle)

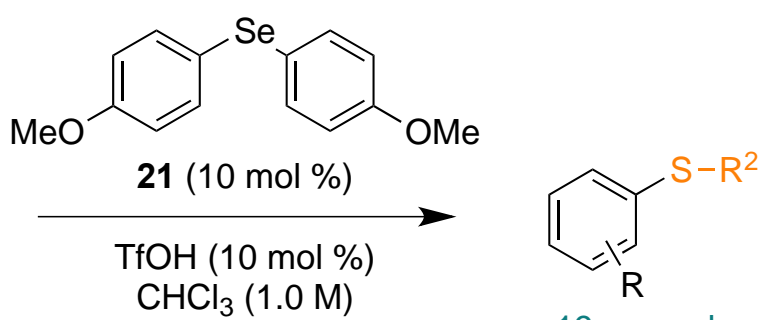

r.t., up to $24 \mathrm{~h}$
19 examples

(applied to FDA approved drugs) $-\mathrm{SCF}_{3}$ and $-\mathrm{N}_{3}$ groups are accessible

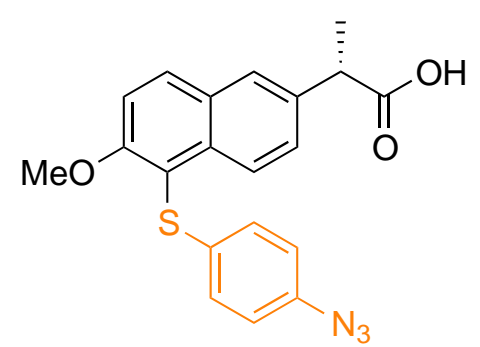

22 (Naproxen) $30 \mathrm{~min}, 76 \%$ yield

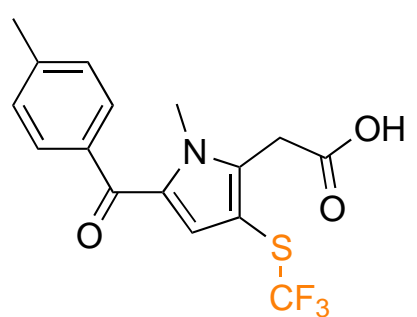

23 (Tolmetin) $16 \mathrm{~h}, 70 \%$ yield

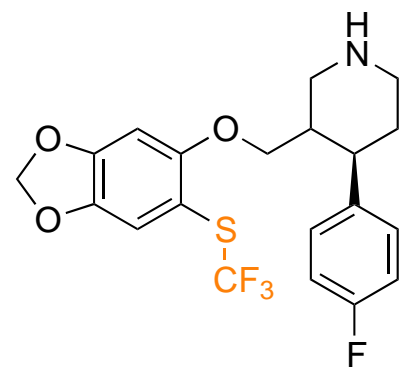

24 (Paroxetine) $45 \mathrm{~min}, 79 \%$ yield

Scheme 5. Lewis base-Brønsted acid catalyzed sulfenylation of pharmaceutically relevant arenes.

\subsection{Photocatalytic ' $\mathrm{C}-\mathrm{H}$ ' Sulfenylation of Aromatics}

A drawback to the above sulfenylation methods is the need for pre-activated sulfenyl sources ${ }^{56}$ such as $N$ thiosuccinimides. The development of new strategies that can activate sulfenyl sources in situ would be of interest for reaction simplicity and efficiency. Radical chemistry via electrochemical and photoredox methods have been popular for $\mathrm{C}-\mathrm{H}$ functionalization. ${ }^{57}$ We hypothesized that sulfur sources could be activated via photocatalytic oxidation to give an electrophilic sulfur species that could be amenable to $\mathrm{C}$ - $\mathrm{H}$ sulfenylation. ${ }^{58}$ We obtained proof of concept for this when we observed that diverse thiobenzamides could be transformed to benzothiazoles (i.e. 25-27) in the presence of $\mathrm{Ru}(\mathrm{bpy}){ }_{3} \mathrm{Cl}_{2}$ and a terminal oxidant (Scheme 6a). Mechanistic and computational studies suggest that this transformation proceeds through initial oxidation of the 
thiobenzamide sulfur which then undergoes radical cyclization. A second oxidation by a persulfate radical anion generates a Wheland arenium ion which then undergoes elimination to give the benzothiazole.

We also observed indole $\mathrm{C}-\mathrm{H}$ sulfenylation using 4-methylbenzenethiol under similar conditions (Scheme 6b). For example, we were able to sulfenylate melatonin to give $\mathbf{2 8}$ in $68 \%$ yield. Mechanistic studies here suggested a different mechanism than the benzothiazole chemistry, wherein the indole is oxidized to a cation that is then nucleophilically attacked by thiophenols to give C-2 or C-3 sulfenylated indole. ${ }^{58}$

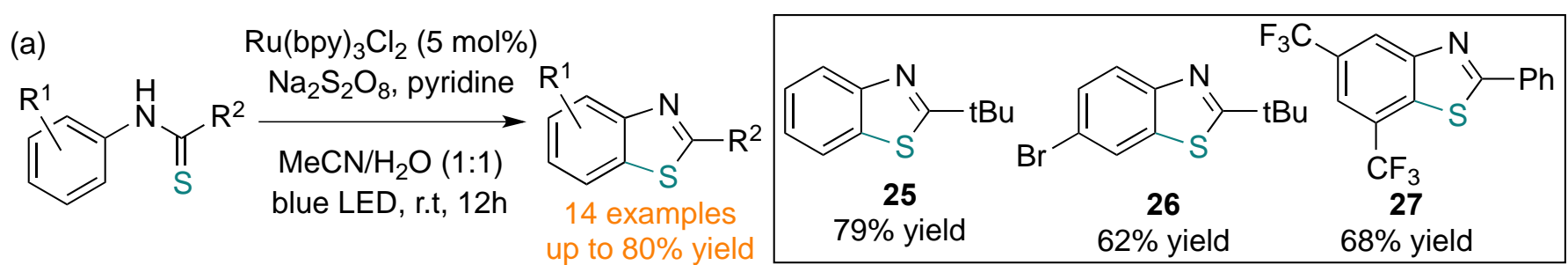

(b) $\quad \mathrm{STOl}=\mathrm{Me}-\mathrm{SH}$

$\left(\operatorname{Ir}\left[\mathrm{dF}\left(\mathrm{CF}_{3}\right) \mathrm{ppy}\right]_{2}(\mathrm{dtbpy})\right) \mathrm{PF}_{6}(1 \mathrm{~mol} \%)$<smiles>[R7]c1cn([R6])c2ccccc12</smiles>

$\mathrm{R}^{2}$

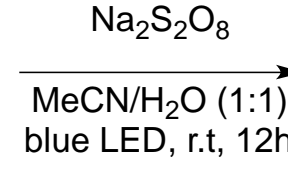<smiles>[R]c1c([Se-])n([R7])c2ccccc12</smiles>

9 examples up to $36 \%$ yield

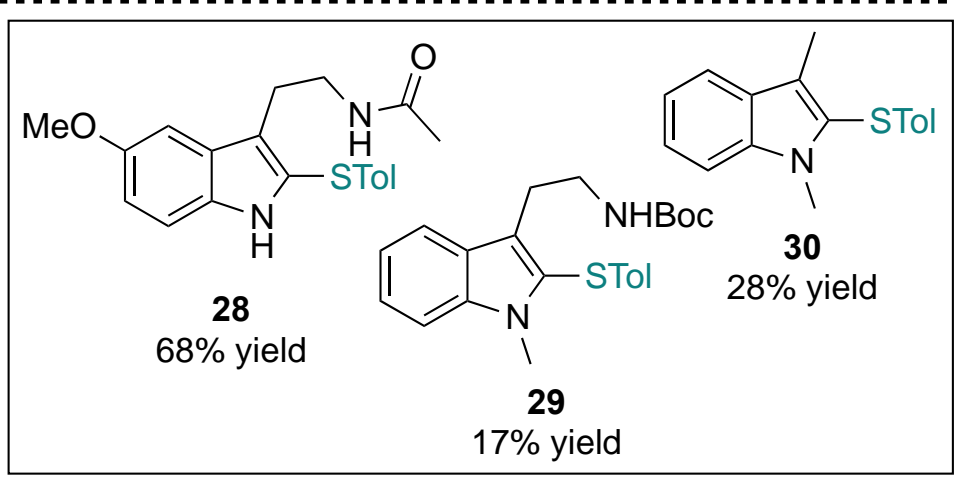

$17 \%$ yield

Scheme 6. (a) The photocatalytic cyclization of thiobenzamides to benzothiazoles and selected examples. (b) The photocatalytic sulfenylation of indoles and selected substrates.

\section{Modulating the Potency and Selectivity of Kinase Inhibitors through the Introduction of Class-3 Atropisomerism}<smiles>COc1cccc(-c2cn(C(C)(C)C)c3ncnc(N)c23)c1</smiles>

31

$$
\begin{aligned}
& \text { RET IC }{ }_{50}(\mathrm{nM}): \quad 128.0 \pm 3 \\
& \text { SRC IC } 50(\mathrm{nM}): \quad 151.0 \pm 9 \\
& \text { ABL IC }{ }_{50}(\mathrm{nM}): \quad 244.5 \pm 19
\end{aligned}
$$<smiles>COc1ccc(Cl)c(-c2c(Cl)n(C(C)(C)C)c3ncnc(N)c23)c1</smiles>

$\left(R_{\mathrm{a}}\right)-32$

$1857 \pm 482$ $5570 \pm 907$ $>10000$<smiles>COc1ccc(Cl)c(-c2c(Cl)n(C(C)(C)C)c3ncnc(N)c23)c1</smiles>

$\left(S_{\mathrm{a}}\right)-32$

$7659 \pm 754$

$1193 \pm 170$ $1432 \pm 210$

Figure 4. Leveraging atropisomerism to improve selectivity and potency of a promiscuous kinase inhibiting scaffold, 3-aryl PPYs 
The mild Lewis base catalyzed $S_{E} A r$ discussed in Section 2 enabled us to begin studies on the biological effect of rigidifying Class-1 bioactives to Class-3 atropisomerically stable bioactives. Our initial work focused on pyrrolopyrimidine-based kinase inhibitors (PPYs), a common and promiscuous kinase inhibitor (KI) scaffold that often possesses at least one Class-1 atropisomeric axis as exemplified by compound 31 (Figure 4). ${ }^{59}$ We developed a scalable racemic synthetic route towards atropisomerically rigidified PPYs wherein the axis was rigidified late stage using a Lewis base catalyzed halogenation. We were able to obtain enantiopure samples of each atropisomer via separation of the enantiomers on a chiral stationary phase. We next determined the stereochemical stability for each series of atropisomers using standard HPLC methods, finding stereochemical stabilities between $28-30 \mathrm{kcal} / \mathrm{mol}$, meaning these compounds existed at the interface between Class-2 and Class-3 stabilities. The lower stereochemical stabilities of these compounds is due to the geometric implications of having a 5-membered ring as part of the atropisomeric system. ${ }^{6}$

We then subjected $\mathbf{3 1}$ and both atropisomers of stereochemically stable $\mathbf{3 2}$ to kinase inhibitor profiling across a panel of tyrosine kinases, finding that the Class-3 atropisomers were more selective than the Class-1 'parent' molecule 31. We then obtained $I C_{50}$ data for $\mathbf{3 1}$ and $\mathbf{3 2}$ across a small panel of kinases consisting of Src, EGFR, Yes, Ret, and Abl, and found that the atropisomers of $\mathbf{3 2}$ possessed notably different activity profiles (Figure 4). While PPY 31 displayed little selectivity towards the kinases tested, PPY $\left(R_{\mathrm{a}}\right)$-32 displayed a preference for RET kinase, and its enantiomer $\left(S_{\mathrm{a}}\right)$-32 displayed a preference for Src and Abl kinases. While the atropisomeric compounds were roughly an order of magnitude less potent than the parent molecule, the improved selectivity represented a proof of concept that the promiscuous activities of a Class-1 atropisomer could be decoupled to specific atropisomer conformations.
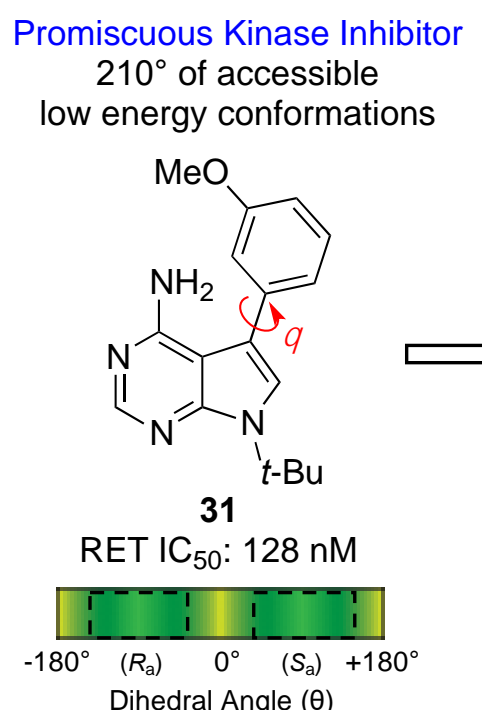

Dihedral Angle $(\theta)$

RET IC ${ }_{50}(\mathrm{nM})$ :

SRC IC $\mathrm{C}_{50}(\mathrm{nM})$ :

EGFR IC $50(\mathrm{nM})$ :

EGFR L858R/T790M/C797S IC 50 (nM):
31

Selective Kinase Inhibitor $80^{\circ}$ of accessible

low energy conformations

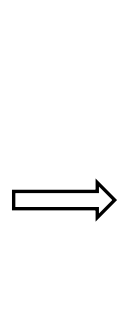

128

151

641

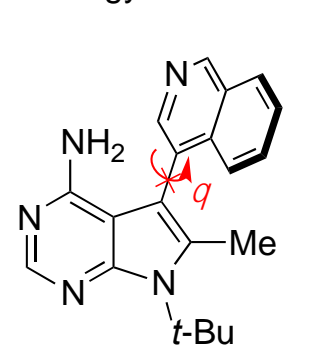

$\left(R_{\mathrm{a}}\right)-33$

RET IC $50: 8 \mathrm{nM}$

8

316

3246

106

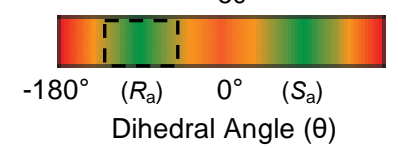

Figure 5. Optimization of a potent and selective RET kinase inhibiting scaffold.

While this work was largely a proof of concept, we were intrigued by the preliminary selectivity of $\left(R_{\mathrm{a}}\right)$ 32 towards RET kinase. RET kinase is a receptor tyrosine kinase whose aberrant activity has been implicated in numerous cancers, such as thyroid cancers, ${ }^{60,61}$ non-small-cell-lung cancer, ${ }^{62,63}$ breast cancers, ${ }^{64}$ and neuroblastoma. ${ }^{65,66}$ While there has been significant interest in the development of RET inhibitors as 
therapeutics, RET selectivity was proven to be a challenge. The lack of selectivity in RET inhibitors is associated with adverse events in patients that are caused by inhibition of kinases other than RET, necessitating the development of more selective RET Inhibitors. Beginning with in silico docking studies on various inhibitors, we were able to come up with several hypotheses that led to notable improvements in selectivity and potency, eventually leading to $\left(R_{\mathrm{a}}\right)$-33 (Figure 5). ${ }^{67}$ Evaluation of the selectivity of $\left(R_{\mathrm{a}}\right)$-33 revealed that it displays 2-3 orders of magnitude of selectivity for RET over myriad kinases including EGFR and VEGFR2, kinases whose offtarget inhibition leads to adverse effects in cancer patients. $\left(R_{\mathrm{a}}\right)$-33 also displayed good antiproliferative effects with low single-digit nanomolar activities in RET-driven models of thyroid cancer, lung cancers, and breast cancers with no off-target effects in cell lines that were not RET-dependent.
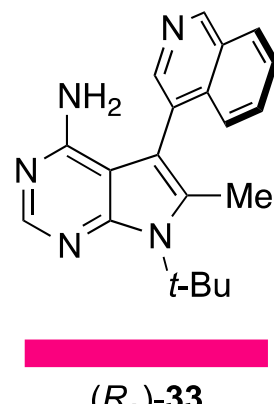

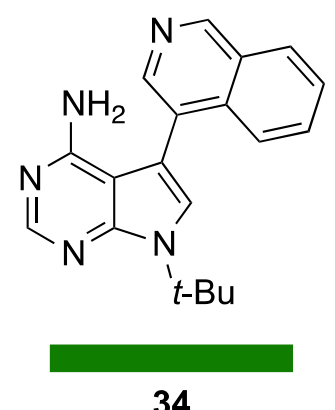

34

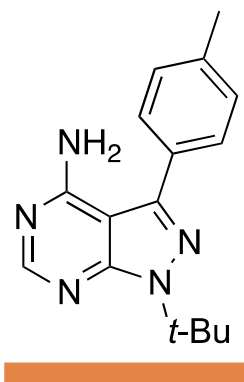

35

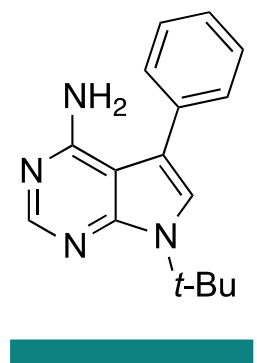

36

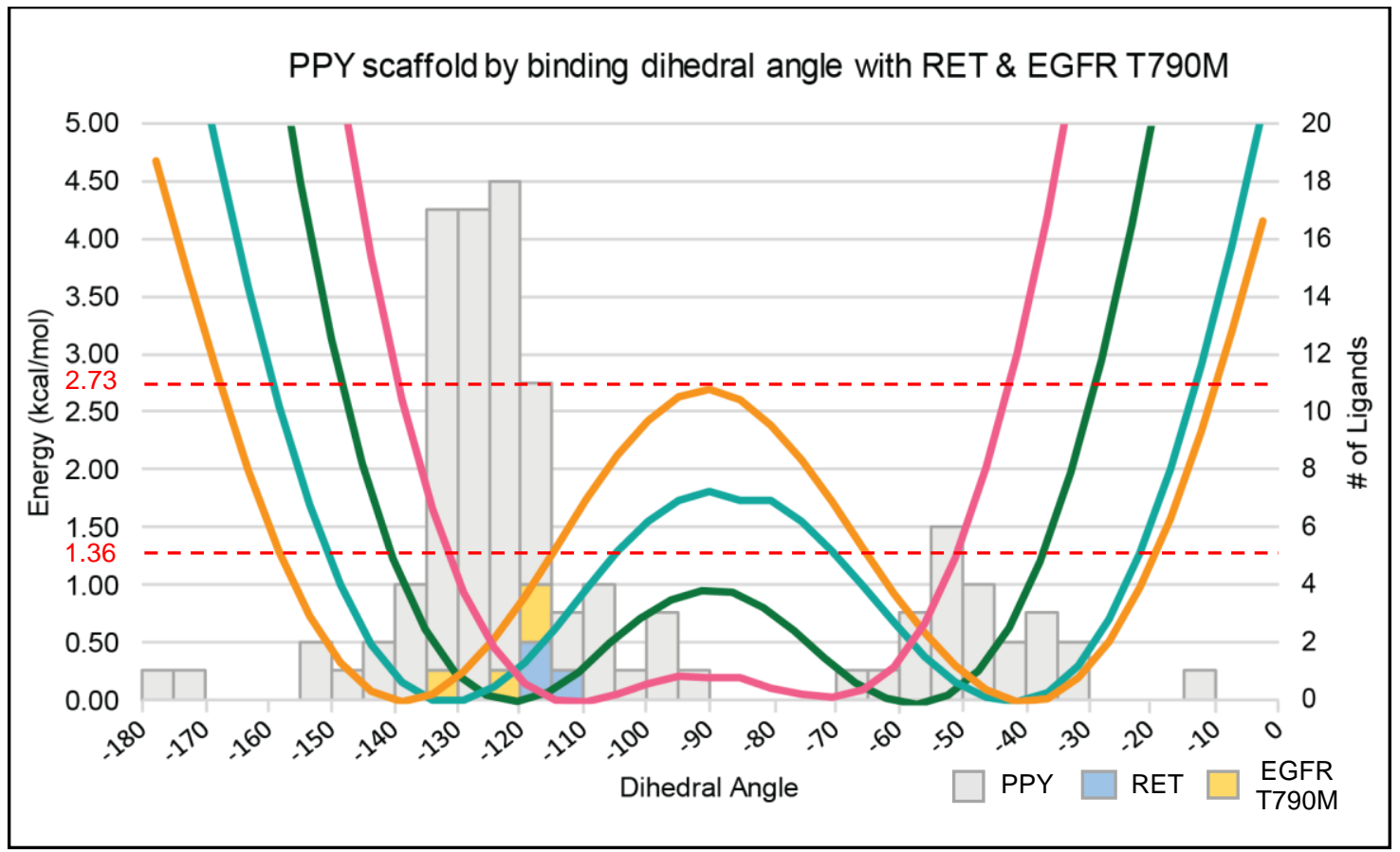

Figure 6. Optimization of a potent and selective RET kinase inhibiting scaffold (blue bar graphs) with secondary EGFR activities (yellow bar graphs). PPY $\left(R_{\mathrm{a}}\right)$-33 (magenta) possesses Class-3 atropisomerism while 34 (green), $\mathbf{3 5}$ (orange) and $\mathbf{3 6}$ (teal) all possess Class-1 atropisomerism.

We next sought out to understand the marked increases in selectivity. Analysis of the predicted conformational energy profile about the atropisomeric axis of a series of PPYs demonstrated that Class-3 atropisomers had significantly restricted windows of accessible dihedral conformations than that of Class-1 atropisomers (Figure 6). When these conformational energy profiles are overlaid with the preferred conformations of over 110 PPYs and similar scaffold bound to kinases in the PDB, it becomes clear that the 
majority observed improvements in RET selectivity and potency are likely due to this narrowing of the lowenergy conformational window accessible to $\left(R_{\mathrm{a}}\right)$-33 (Figure 6, narrowing of the magenta curve). For example, the Class-1 atropisomer promiscuous kinase inhibitor PP1 35 has roughly $85 \%$ of the observed binding conformations from the PDB fall within $1.3 \mathrm{kcal} / \mathrm{mol}$ of its predicted conformational ground states. In contrast, less than $60 \%$ of the observed PDB conformations fall within $1.3 \mathrm{kcal} / \mathrm{mol}$ of the predicted ground state conformations of $\left(R_{\mathrm{a}}\right)$-33. Furthermore, the preferred conformations of these scaffolds bound to RET corresponds to the more orthogonal predicted ground state conformation of $\left(R_{\mathrm{a}}\right)$-33. While these effects may not be a direct consequence of introducing atropisomerism, rigidifying the axis to synthesize stereochemically stable compounds is likely needed to design inhibitors that favor conformations approaching orthogonality. Furthermore, we acknowledge that adding 'blocking groups' may lead to new interactions which may also lead to the observed changes in potency and selectivity. This work is certainly an application of the magic methyl effect and, in seminal work from Jorgenson, ${ }^{68}$ it is demonstrated that the majority of 'Magic-Methyl' effects are caused by conformational changes in line with what we propose.

To further test our hypothesis, we evaluated $\left(R_{\mathrm{a}}\right)$-33 against kinases that were predicted to prefer conformations similar to RET. Notably these kinases included oncogenic mutations of EGFR, but not Wild-type EGFR. Mutant EGFRs have been a long-standing target for drug discovery, with three generations of FDA approved drugs in the clinic. Despite this, there is no truly mutant selective inhibitor currently available, which causes an issue in patients as WT EGFR is an essential kinase in several canonical signaling pathways and its inhibition leads to several grade 3 and grade 4 adverse effects in patients. Furthermore, the current EGFR inhibitors in the clinic lack efficacy towards an emerging triple mutant (L858R/T790M/C797S) that occurs in roughly a third of patients on third generation EGFR inhibitors. As such, there is a great need for a $4^{\text {th }}$ generation EGFR inhibitor that possesses high mutant over wild type selectivity while maintaining activity towards the triple mutant. Due to these issues, and the fact that EGFR mutants bind their targets in conformations similar to RET, we evaluated $\left(R_{\mathrm{a}}\right)$-33 against the leading oncogenic EGFR mutants, finding low double digit nanomolar potencies across the board, with 2-3 orders of magnitude preference for the mutants over wild type. Notably these potencies and selectivities held in cellular models of EGFR driven cancers.

\section{Developing Atroposelective Synthetic Methods Towards Pharmaceutically Relevant Scaffolds}

Our work on introducing atropisomerism as a design element to modulate the potency and selectivity of small molecule bioactives proceeded through the racemic synthesis of the atropisomer followed by chiral resolution, typically via chiral HPLC. Because of this, access to atropisomerically pure scaffolds has represented one of the major bottlenecks that we have faced. Catalytic atroposelective syntheses of pharmaceutically relevant scaffolds would represent a more efficient and scalable approach. However, the majority of examples of catalytic atroposelective synthesis in the literature have focused on biphenyls or binaphthyl-based atropisomers. While there are some reports of the atroposelective syntheses of heterobiaryl scaffolds, ${ }^{69-72}$ the enantioselective syntheses of the vast majority of pharmaceutically relevant potentially atropisomeric heterobiaryl systems have not been studied in depth. As such our group has begun to focus on the development of new strategies towards the atroposelective synthesis of pharmaceutically relevant scaffolds. 


\subsection{Atroposelective nucleophilic aromatic substitution $\left(S_{N} A r\right)$ strategies towards 3-aryl PPYs}

Nucleophilic aromatic substitution $\left(S_{N} A r\right)$ is among the most used reactions in modern drug discovery ${ }^{73}$ as diverse relevant functionalities can be introduced into pharmaceutically relevant heterocycles via $S_{N} A r$. In 2015 , the Smith group disclosed an atroposelective desymmetrization of biaryl pyrimidines via chiral cationdirected $S_{N} A r$ of thiophenols (Scheme 7). ${ }^{74}$ This work represented the first example of atroposelective $S_{N} A r$ and furnished atropisomeric pyrimidines such as $\mathbf{3 8}$ and $\mathbf{3 9}$ in excellent yields and selectivities.<smiles>[X]c1ccccc1-c1c([R])nc(Br)nc1[X]</smiles>

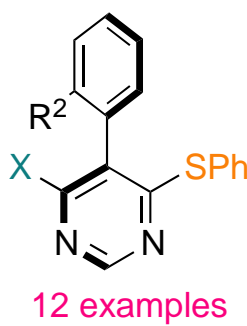

up to $97: 3$ e.r. $24-97 \%$ yields

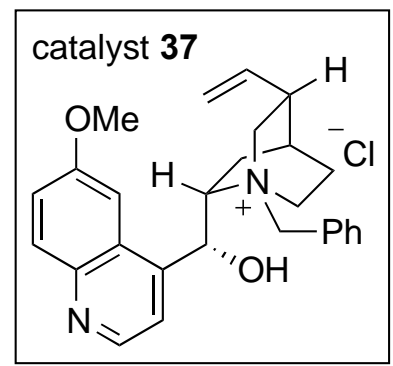

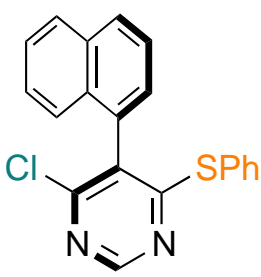

38

$93 \%$ yield 97:3 e.r.

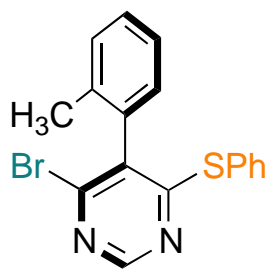

39 $92 \%$ yield 93:7 e.r.

Scheme 7. Desymmetrization of biaryl pyrimidines via atroposelective cation-catalyzed $\mathrm{S}_{N} A r$.

Inspired by Smith's work, we developed an atroposelective $\mathrm{S}_{N} \mathrm{Ar}$ strategy towards 3-aryl PPY kinase inhibitors via kinetic resolution (KR) (Scheme $8 a$ ). ${ }^{75}$ Similar to the findings from the Smith group, we found that quaternary ammonium chloride salts derived from quinine, such as $\mathbf{3 7}$, to be selective catalysts, however this chemistry performed best in aprotic solvents in the absence of water. The optimal catalyst and conditions were amenable to a number of structurally diverse PPYs and common perturbations that may be encountered in a medicinal chemistry campaign. For example, the $N$-substitution off of the pyrrolopyrimidines $\left(R^{1}\right)$ could be diverse alkyl groups with minimal perturbation in selectivity given by s-factor (40 and 41), the 3-aryl group could also be modified to myriad aryl groups as in $\mathbf{4 2}$. The $C-2$ position $\left(R^{2}\right)$ proved most sensitive with strongly electron withdrawing groups (i.e. nitro) leading to poor selectivity due to a significant background reaction, and electron donating substituents (i.e. alkyl groups) leading to minimal conversions to product. Nonetheless, this chemistry was amenable to substitutions such as $\mathrm{Cl}, \mathrm{Br}(\mathbf{4 3})$, and the difluoromethyl group (44).

Importantly, we found that both the recovered starting material, and the sulfide products could be transformed without racemization into the pharmaceutically relevant aminopyrimidines with no observed racemization via a 2 or 3 -step process (Scheme $8 \mathrm{~b}$ ). While the sensitivity of this reaction to substitution at the C-2 is a limitation, we found that substrates with C-2 halogen substitution could be easily transformed to alkylated $(45,47)$ and arylated $(46)$ analogs using known cross-coupling conditions (Scheme $8 \mathrm{c}){ }^{76}$ Finally, It should be noted that simple trituration allowed us to augment the isolated e.r.s to greater than 99:1. 

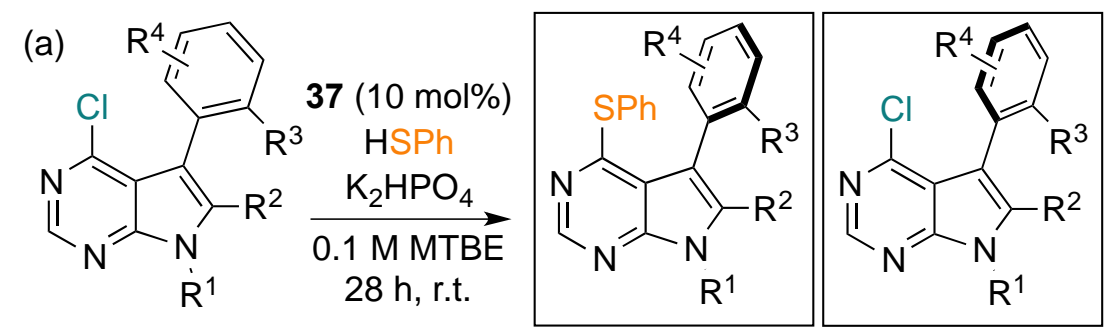

Summary of results:

- 16 examples

- $s$-factors up to 58

- Both recovered SM and product can be transformed to aminated kinase inhibitor with no racemization

- Trituration can improve e.r. up to 99:1 e.r.
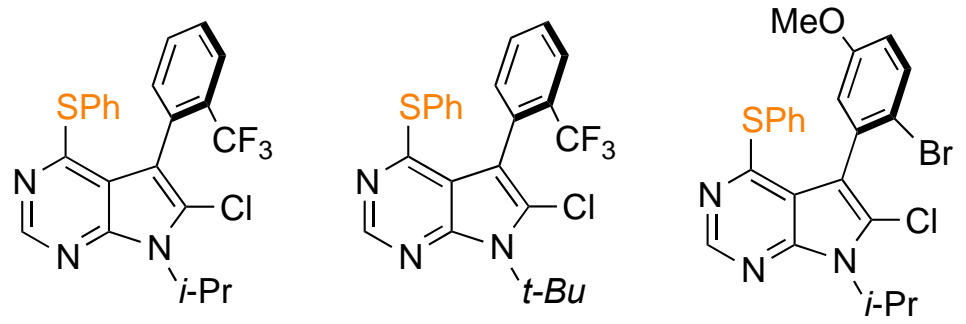

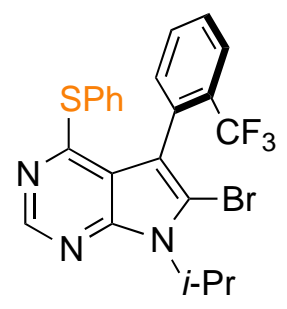

$\left(R_{\mathrm{a}}\right)-\mathbf{4 2}$ $\mathrm{S}=17.1$

$\left(R_{\mathrm{a}}\right)-43$

$\mathrm{S}=58$

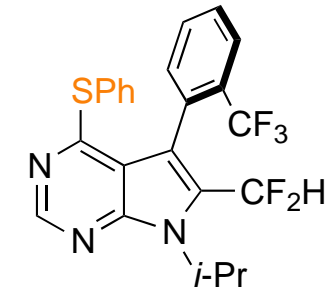

$\left(R_{\mathrm{a}}\right)-\mathbf{4 4}$

$\mathrm{S}=28.3$ $\mathrm{S}=29.1$

$\mathrm{S}=11.5$

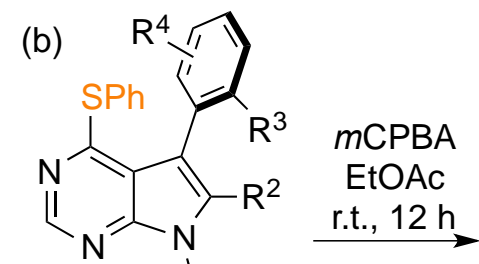

$\mathrm{R}^{1}$

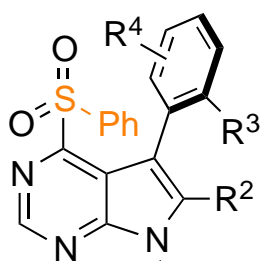

$\dot{R}^{1}$
1)<smiles>COc1ccc(CN)c(OC)c1</smiles>

$\mathrm{CH}_{2} \mathrm{Cl}_{2}$, r.t., 24-48 h

2) $\mathrm{CF}_{3} \mathrm{CO}_{2} \mathrm{H}, \mathrm{CH}_{2} \mathrm{Cl}_{2}$ r.t., $12 \mathrm{~h}$

3) trituration, $n$-hexane

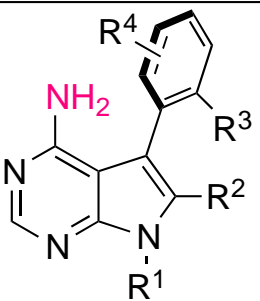

4 examples no observed racemization $<96: 4$ e.r., $24-84 \%$ $>99: 1$ e.r. after trituration<smiles>[R]c1ccccc1-c1c([Y])n(CC(Br)Br)c2ncnc(N)c12</smiles>

1) $\mathrm{Boc}_{2} \mathrm{O}$, DMAP (10 mol\%), $0.1 \mathrm{M}$ THF, r.t., $24 \mathrm{~h}$

2) Pd catalyzed cross-coupling

3) $\mathrm{CF}_{3} \mathrm{CO}_{2} \mathrm{H}, \mathrm{CH}_{2} \mathrm{Cl}_{2}$ r.t., $12 \mathrm{~h}$<smiles>[R]c1ccccc1-c1c(N)n(C(C)C)c2ncnc([R])c12</smiles>

\begin{tabular}{|c|c|c|c|c|}
\hline Entry & $\mathrm{R}^{2}$ & $\mathrm{R}^{3}$ & e.r. & yield(\%) \\
\hline 45 & $\mathrm{Me}$ & $\mathrm{CF}_{3}$ & $94: 6$ & 53 \\
46 & $\mathrm{Ph}$ & $\mathrm{CF}_{3}$ & $92: 8$ & 70 \\
$\mathbf{4 7}$ & $\mathrm{Me}$ & $\mathrm{NA}$ & $85: 15$ & 58 \\
\hline
\end{tabular}

$\mathrm{NA}=$ naphthyl

Scheme 8. (a) Atroposelective $S_{N} A r$ of 3-aryl PPYs. (b) Some examples from the substrate evaluation. c) Route towards amination of products without racemization. Recovered starting materials are also able to undergo this amination strategy. (d) Modern coupling conditions yield desired electron-rich PPYs, such as C-2 methyl or C-2 phenyl PPYs without any observable racemization.

\subsection{Atroposelective vicarious nucleophilic substitution (VNS)-like strategies towards atropisomeric naphthoquinones}

One drawback of the aforementioned atroposelective $S_{N} A r$ is that the isolated yield is limited to $50 \%$ in an ideal situation by the kinetic resolution (KR) character of the reaction. We hypothesized that vicarious nucleophilic substitution (VNS) would allow for a 'dynamic kinetic resolution' (DKR) wherein a Class-1 atropisomer is rigidified to a Class-3 atropisomer. Along these lines, it is known that various nucleophiles, including thiophenols, can add into unsubstituted quinones and naphthoquinones in a process similar to VNS. ${ }^{77,78}$ Inspired by this reactivity, we sought to determine if thiophenols could be added atroposelectively into aryl-substituted naphthoquinones (Scheme 9a). ${ }^{79}$ 
We quickly found that quinine derived catalysts possessing a sterically hindered benzamide off of the C-9 position (such as 48) could affect the addition of diverse thiophenols into aryl substituted naphthoquinones in good yields and selectivities, however the recovered products possessed barriers to rotation around $26 \mathrm{kcal} / \mathrm{mol}$, leading to spontaneous racemization on the month time scale at room temperature (Scheme $9 \mathrm{~b}$ ). On the other hand, reduction of the products to the alkylated hydroquinone such as $\mathbf{5 7}$ or $\mathbf{5 8}$ led to products that were significantly more stereochemically stable ( $36 \mathrm{kcal} / \mathrm{mol})$. The dramatic increase in stereochemical stability of hydroquinones compared to quinones is in line with previous observation from Regan in the context of the total synthesis of Bismurrayquinone $A .{ }^{80}$ Gratifyingly we found simply running the thiophenol addition at $0{ }^{\circ} \mathrm{C}$ and performing an alkylative reductive quench allowed us to access several diverse (49-53) stereochemically stable products in excellent overall yields and enantioselectivities above 95:5 e.r. (Scheme 9c).

(a)

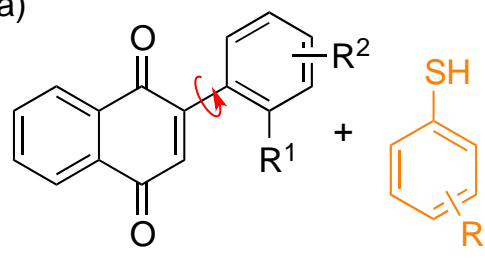

1) $48(5 \mathrm{~mol} \%)$, $0.05 \mathrm{M} \mathrm{PhMe}$ $4^{\circ} \mathrm{C}, 20 \mathrm{~h}$

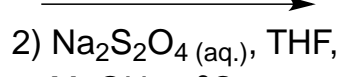
$\mathrm{MeOH}, 0^{\circ} \mathrm{C}$

3) $\mathrm{KOH}_{(\text {(aq.) }}, \mathrm{Me}_{2} \mathrm{SO}_{4}$

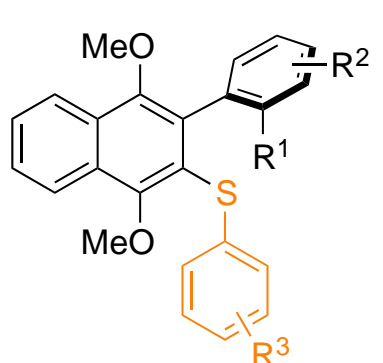

$\mathrm{R}^{3}$

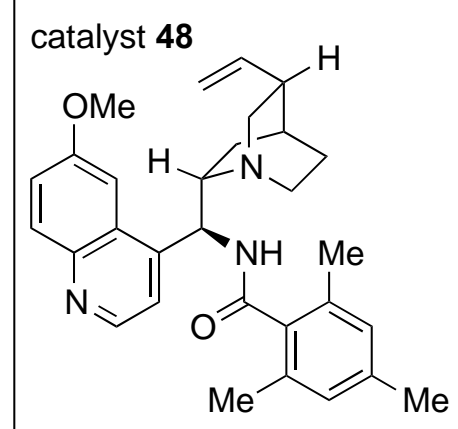<smiles>COc1c(Sc2ccccc2C)c(-c2ccccc2C(F)(F)F)c(OC)c2ccccc12</smiles>

49

$96: 4$ e.r., $82 \%$

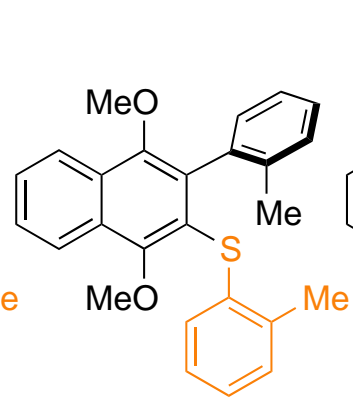

50

96:4 e.r., $82 \%$

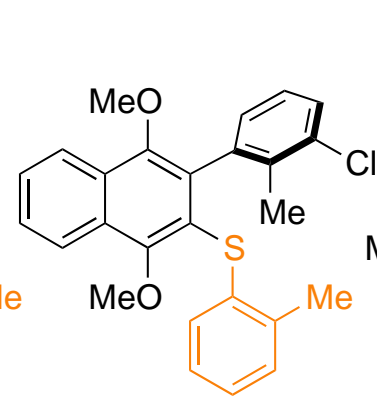

51

$88: 12$ e.r., $83 \%$

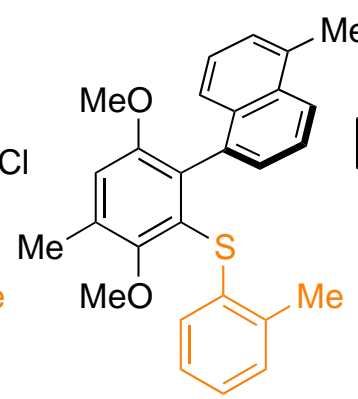

52

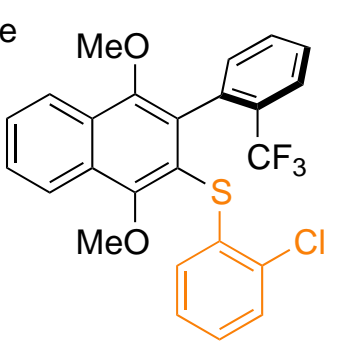

53

$93: 7$ e.r., $86 \%$ [gram-scale] 92:8 e.r., $95 \%$ $(>99.5: 0.5 \text { e.r., } 82 \%)^{*}$ trituration

(c)<smiles>[X]C1=C(c2ccccc2C(F)(F)F)C(=O)c2ccccc2C1=O</smiles><smiles>[As]=[Sn][SnH3]</smiles>

$55\left(\mathrm{X}=\mathrm{SO}_{2} \mathrm{Ph}\right)$ $\mathrm{G}_{\mathrm{rac}} \sim 26 \mathrm{kcal} / \mathrm{mol}$<smiles>O=S(=O)(c1ccccc1)c1c(-c2ccccc2C(F)(F)F)c(O)c2ccccc2c1O</smiles>

56

$\mathrm{G}_{\mathrm{rac}} \sim 36 \mathrm{kcal} / \mathrm{mol}$<smiles>[X]c1c(-c2ccccc2C(F)(F)F)c(OC)c2ccccc2c1OC</smiles>

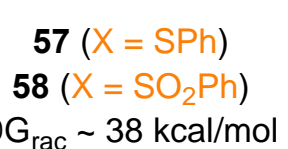

Summary of results:

- 27 examples, 1 example on gram-scale - $<98.5: 1.5$ e.r., $<99 \%$ yield

->99.5:0.5 after recrystallization

Scheme 9. (a) Atroposelective VNS-like reaction towards naphthoquinone biaryls. (b) Selected examples from our substrates evaluation. (c) Comparing the stereochemical stabilities of resulting sulfides their various oxidation states. 


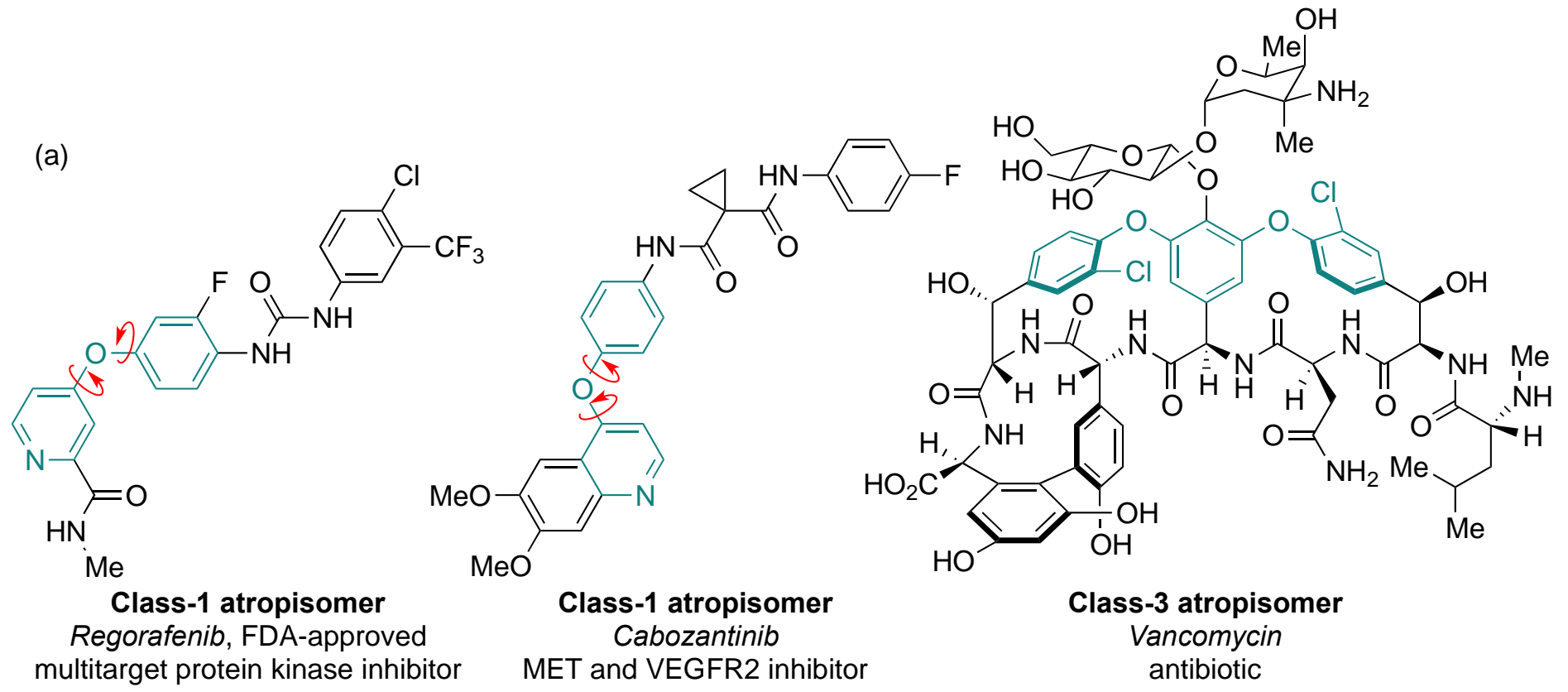

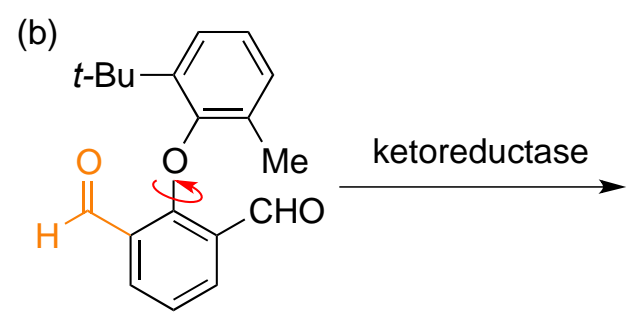

59

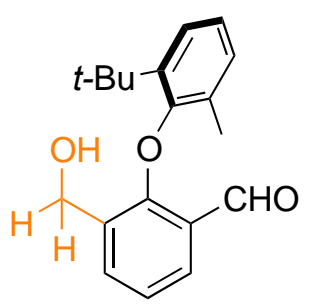

60

6 examples

$<85: 15$ e.r., $<80 \%$ yield

$>95: 5$ via recrystallization

Scheme 10. Diaryl ethers are a common scaffold in drug discovery. (a) Examples of atropisomeric diaryl ethers in medicine. (b) Clayden and Turner's desymmetrization of diaryl ethers via biocatalytic reduction.

We also studied the quinone VNS strategy in the context of $O$-aryl quinoids, a scaffold that is closely related to diaryl ethers. Diaryl ethers and related scaffolds are a somewhat common pharmacophore that possess the potential for atropisomerism. For example, the FDA-approved kinase inhibitor Regorafenib possesses a Class-1 diaryl ether atropisomeric axis, ${ }^{65,81}$ Cabozantinib possesses a 'pro-chiral' diaryl ether axis, $^{81,82}$ and the venerable antibiotic Vancomycin possesses two Class-3 diaryl ether atropisomeric axes (Scheme 10a). ${ }^{83,84}$ Despite this the asymmetric synthesis of diaryl ethers and related compounds have been relatively understudied, likely due to the fact that diaryl ethers represent a '2-axes' system, which Clayden has demonstrated result in the possibility for a concerted gearing mechanism of racemization that occurs at a lower energy level, resulting in diaryl ethers posing lower stereochemical stabilities than biaryls. Nonetheless, Clayden has found that diaryl ethers with four ortho-substituents, and at least one tertiary alkyl group (i.e. $t \mathrm{Bu}$ ) can exist as Class-3 atropisomers. He subsequently worked with the Turner group to develop a biocatalytic desymmetrization that allowed access to enantiopure diaryl ethers as exemplified by the transformation of $\mathbf{5 9}$ to $\mathbf{6 0}$ (Scheme 10b). ${ }^{85}$ As of this writing, this is the only example of the enantioselective synthesis of diaryl ethers. 


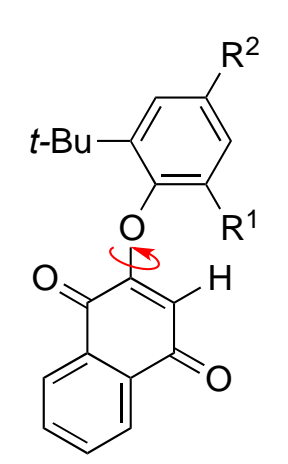

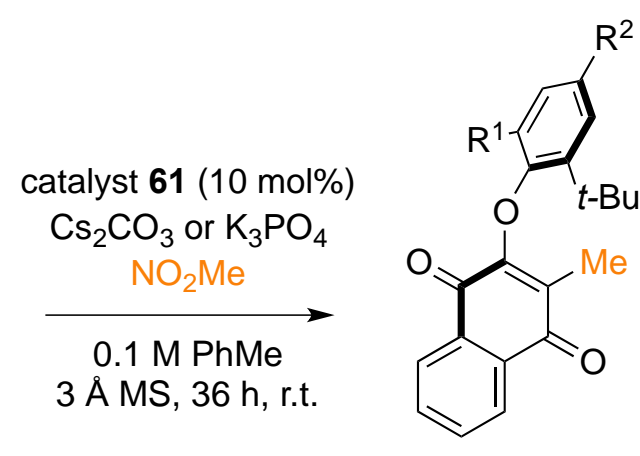

6 examples

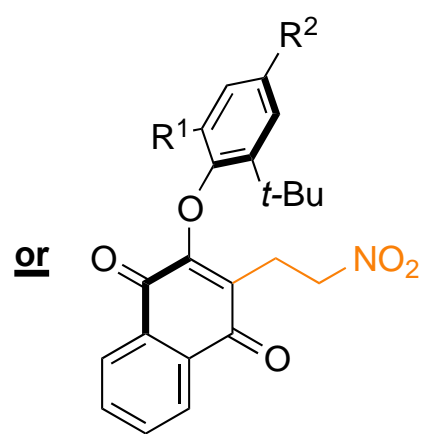

5 examples

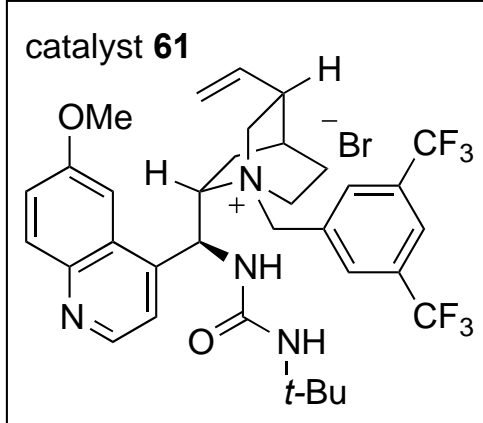

$<85: 15$ e.r., $<80 \%$ yield $<78: 22$ e.r., $3-68 \%$ yields

$>95: 5$ via recrystallization $>99: 1$ via recrystallization

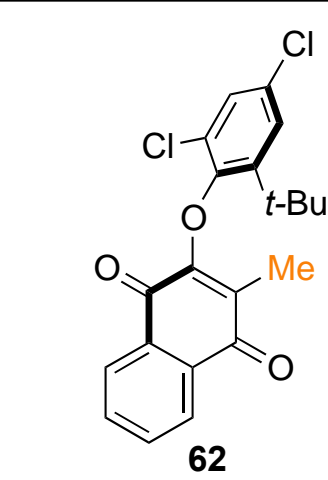

$82: 18$ e.r., $68 \%$ yield $97: 3$ e.r., $41 \%$ yield ${ }^{* *}$ (** via recrystallization)

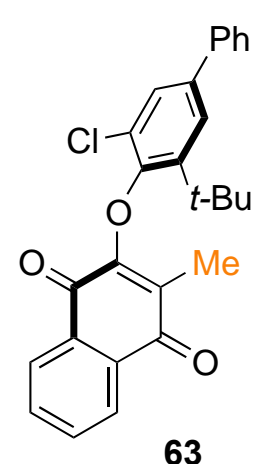

72:28 e.r., $47 \%$ yield

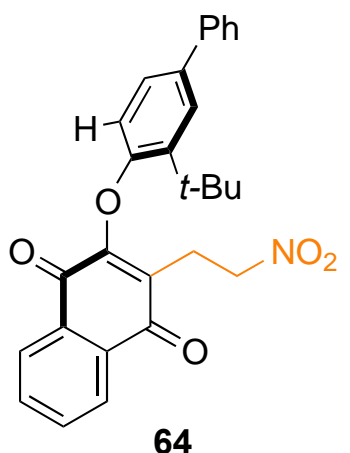

$75: 25$ e.r., $65 \%$ yield

Scheme 11. Atroposelective VNS towards $O$-aryl quinoids using nitromethane.

Inspired by these precedents, we designed a class of $O$-aryl quinoids (Scheme 11 ) and sought to determine if we could develop a catalytic enantioselective VNS-like strategy to access stereochemically stable products. While the addition of thiophenols did not prove fruitful, we found that we could affect atroposelective methylation on this scaffold using nitromethane as the methyl source (Scheme 11), ${ }^{86}$ in line with chemistry from Mukherjee. ${ }^{87,88}$ In this work, sterically hindered ureas containing quinine derivatives such as 61 were found to effect the alkylation in good yields and moderate to good enantioselectivity (up to 85:15 e.r.). The moderate enantioselectivity was perhaps due to the products existing as Class- 2 atropisomers with barriers to racemization between $25-28 \mathrm{kcal} / \mathrm{mol}$ due to the aforementioned gearing mechanism to racemization. Nonetheless, the enantiopurity of the alkylated products could be amplified to greater than 95:5 e.r. via trituration. It should be noted that several of the evaluated substrates resulted in a competing 'nitroethylated' byproduct (i.e, 64) with similar enantioselectivities up to 78:22 e.r. and up to 68\% yield.

\subsection{Atroposelective Lewis acid catalyzed halogenation towards atropisomeric $\mathbf{N}$-aryl quinoids}

Based on our work on diaryl ethers, we were motivated to study other two axes systems and develop atroposelective strategies to access them. The diaryl amine scaffold is perhaps the most common 2-axis atropisomeric system in drug discovery. Indeed, a cursory PDB search reveals thousands of potentially atropisomeric diaryl amines bound to diverse biological targets. As with diaryl ethers, the dual axial nature leads to a complex conformational profile as well as a potential gearing mechanism that can lead to lower 
than expected barriers to racemization. ${ }^{89}$ Clayden has recently reported a detailed study on the conformational stability of 2,2'-di-ortho-substituted diarylamines, wherein they observed that the size of ortho substituents on the different aryl rings can have a marked effect on the conformational profile, with larger substituents leading to a more perpendicular preferred conformation, and the possibility for stereochemical stability as demonstrated with compound 65 and $\mathbf{6 6}$ (Scheme 12a). ${ }^{90}$ Work by Kawabata has demonstrated that the stereochemical stability of diaryl amines could be increased by an intramolecular $\mathrm{N}-\mathrm{H}$ $\mathrm{N}$ hydrogen bond (Scheme 12b). ${ }^{91}$ Essentially, the hydrogen bond locked one of the atropisomeric axes into a planar conformation, preventing "gearing" mechanism of racemization. It should be noted that Kawabata observed that diaryl amine stereochemical stability was dependent on the strength of the intramolecular hydrogen bond, with weaker interactions leading to stereochemical instability. More recently, Clayden resolved the atropisomers for diarylamines without an internal H-bond, finding them typically to exist as Class1 or Class-2 atropisomers. $^{70}$

(a) Clayden's atropisomeric diaryl amines

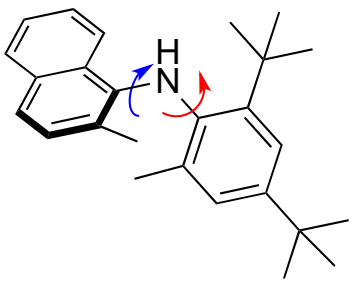

65

$\mathrm{G}_{\mathrm{rac}}=31.1 \mathrm{kcal} / \mathrm{mol}$

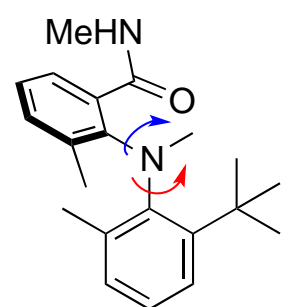

66

$\mathrm{G}_{\mathrm{rac}}=25.5 \mathrm{kcal} / \mathrm{mol}$ (b) Kawabata's strategy

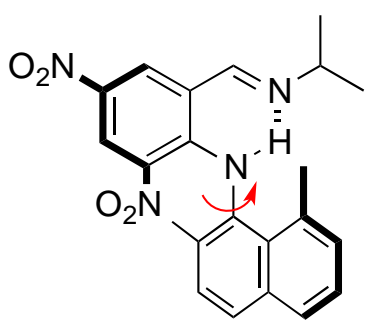

67

$\mathrm{G}_{\mathrm{rac}}=28.2 \mathrm{kcal} / \mathrm{mol}$

Scheme 12. Previous work on atropisomerically stable diaryl amines

To the date of writing this account there is not a single example reported in the literature on the enantioselective synthesis of axially chiral diaryl amines. Inspired by Kawabata's work on hydrogen bonding dependent stability of biaryl anilines, we designed $N$-aryl quinoids such as 68 (Scheme 13) that possess a 5 membered intramolecular $\mathrm{N}-\mathrm{H}-\mathrm{O}$ hydrogen bond, however it exists as a Class-1 atropisomer. We then observed that halogenation of the 'enamine-like' naphthoquinone $\mathrm{C}-\mathrm{H}$ of 68 led to 69, which existed as a stereochemically stable Class-3 atropisomers with a barrier to racemization exceeding $30 \mathrm{kcal} / \mathrm{mol}\left(t_{1 / 2\left(37^{\circ} \mathrm{C}\right)}>\right.$ 4.5 years) in both protic and aprotic solvents.

We next sought to translate this halogenation into an enantioselective route. Inspired by work from Akiyama, we evaluated several chiral phosphoric acids (CPA) with $N$-bromosuccinimide (NBS) for the bromination of 68 . Initially, the venerable CPA $(R)$-TRIPS 70 effected this reaction to near quantitative conversions with promising enantioselectivity (77:23 e.r.). After evaluating eleven different catalysts we found that octahydro-BINOL (H8-BINOL) CPA 71, which possesses 1-naphthyl substitution at the 3,3' position, to be an effective catalyst yielding brominated product 69 in 95\% yield and an e.r. of 96:4. The chemistry proved to be tolerant to diverse substitutions of the 2,4-positions of the aniline, with electron rich 2,4 diaryl substitutions as seen in $\mathbf{7 2}$ and $\mathbf{7 3}$ yielding e.r.s >95:5, and electron deficient 2,4 diaryl substitutions typically yielding e.r.s $>89: 11$ in good yields. Fused heterocyclic ring systems such as 2-benzothiophines (74) also resulted in good yields and <95:5 e.r. We found that anilines that possess a less bulky group such as $i$-Pr (75) at the 6-position resulted in good yield but drastic decreases in e.r. to 64:36 likely due to a low barrier to racemization (measured to be $24 \mathrm{kcal} / \mathrm{mol}$ ) for these substrates leading to racemization during the course of 
the reaction. We also found that this chemistry could be translated to chlorination and iodination of $N$-aryl quinoids in good enantioselectivities with e.r.s $>80: 20$.
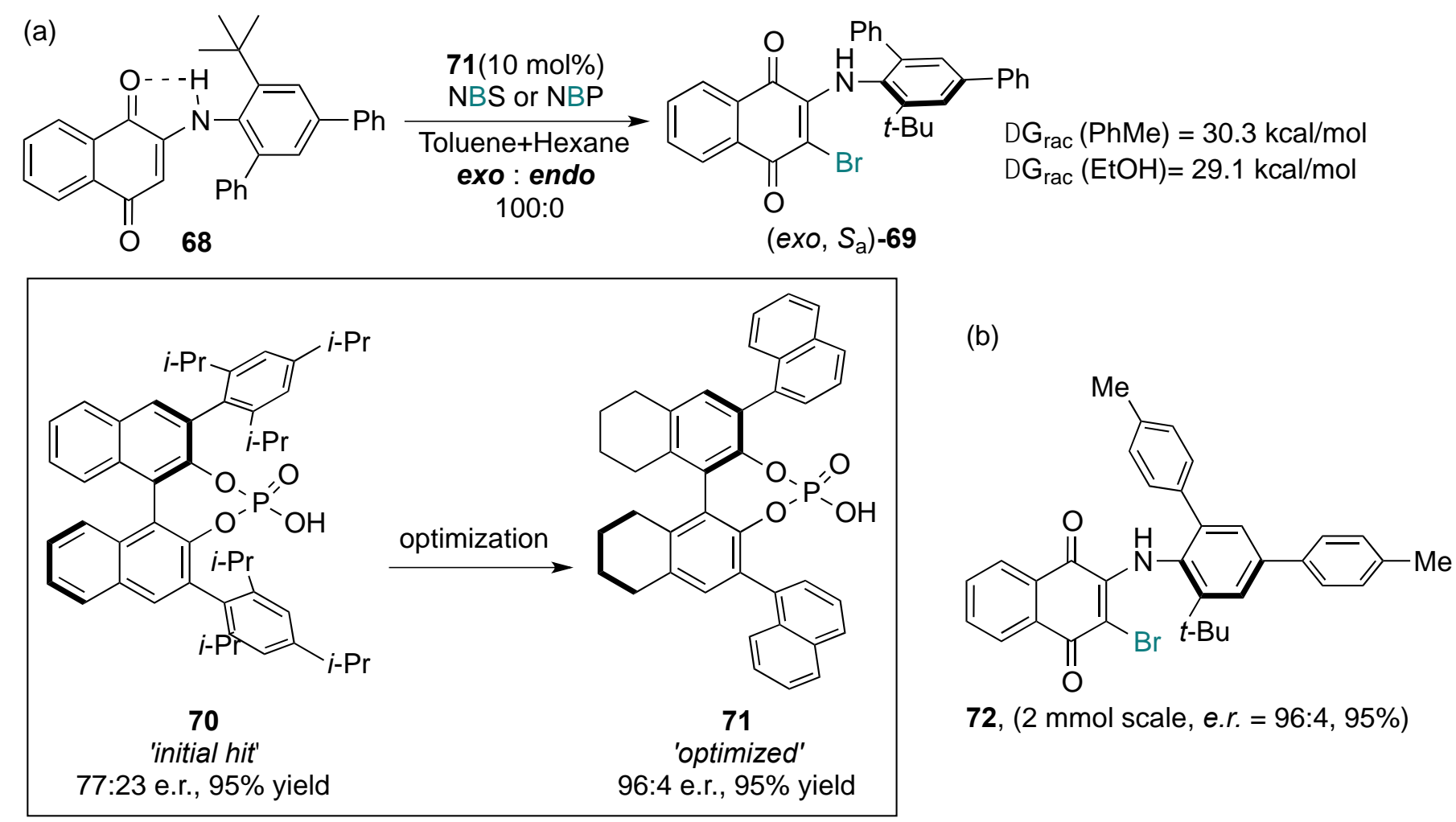

72, $(2 \mathrm{mmol}$ scale, e.r. $=96: 4,95 \%)$

(b) cont.

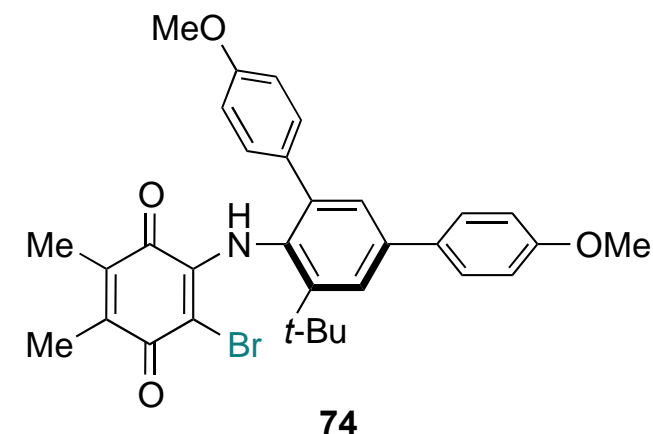

98:2 e.r., $90 \%$ yield<smiles>CC(C)(C)c1cc(Cl)cc(-c2cc3ccccc3s2)c1NC1=C(Br)C(=O)c2ccccc2C1=O</smiles>

95:5 e.r., $86 \%$ yield

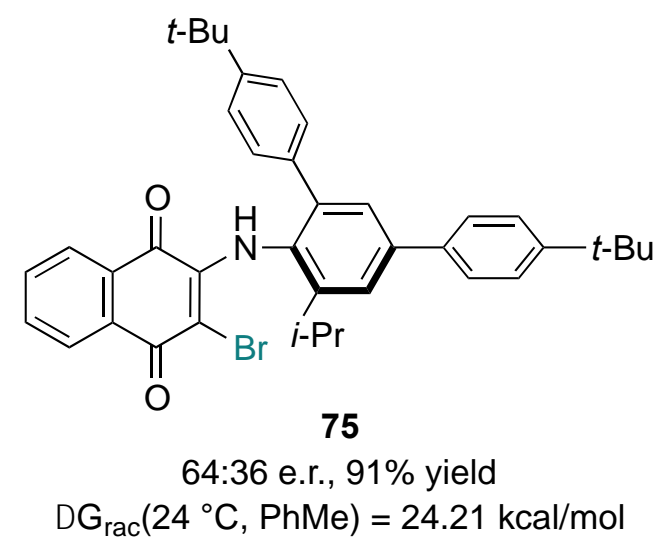

Scheme 13. Atroposelective phosphoric acid catalyzed bromination of $\mathrm{N}$-aryl quinoids.

\section{Conclusions}

Atropisomerism is ubiquitous throughout modern drug discovery however is often overlooked. We have demonstrated that the introduction of stable atropisomerism can lead to marked improvements in the potency and selectivity of kinase inhibitors. The syntheses of these compounds led us to study Lewis bases as catalysts for mild $S_{E} A r$, with a focus on halogenation and sulfenylation. Importantly, we found that Lewis base catalysis represented an entry to catalyst controlled regioselective $S_{E} A r$, which we have demonstrated in the context of halogenation. Finally, the need for access to enantiopure samples of atropisomers for our chemical biology studies led us to pursue several diverse projects focusing on the atropisomer selective synthesis of 
pharmaceutically relevant scaffolds through atroposelective $S_{N} A r$ and related processes. While the projects we have embarked on may seem disparate at times, they have all revolved around and have been inspired by the study of atropisomerism.

\section{Acknowledgements}

We are grateful that our work on atropisomerism was funded by NIGMS (R35GM124637), and our work on the functionalization of aromatics was funded by the National Science Foundation (Grants No. Che-1664565 and Che-1955086).

\section{References}

1. Toenjes, S. T.; Gustafson, J. L. Future Med. Chem. 2018, 10 (4), 409-422. https://doi.org/10.4155/fmc-2017-0152

2. Clayden, J. Org. Synth. Set 2008, 48-52.

3. Kumarasamy, E.; Raghunathan, R.; Sibi, M. P.; Sivaguru, J. Chem. Rev. 2015, 115 (20), 11239-11300. https://doi.org/10.1021/acs.chemrev.5b00136

4. Iida, A.; Matsuoka, M.; Hasegawa, H.; Vanthuyne, N.; Farran, D.; Roussel, C.; Kitagawa, O. J. Org. Chem. 2019, 84 (6), 3169-3175. https://doi.org/10.1021/acs.joc.8b03043

5. Kikuchi, Y.; Nakamura, C.; Matsuoka, M.; Asami, R.; Kitagawa, O. J. Org. Chem. 2019, 84 (12), 8112-8120. https://doi.org/10.1021/acs.joc.9b00989

6. Alkorta, I.; Elguero, J.; Roussel, C.; Vanthuyne, N.; Piras, P. Atropisomerism and Axial Chirality in Heteroaromatic Compounds; 2012; Vol. 105. https://doi.org/10.1016/B978-0-12-396530-1.00001-2

7. Hirai, M.; Terada, S.; Yoshida, H.; Ebine, K.; Hirata, T.; Kitagawa, O. Org. Lett. 2016, 18 (21), 5700-5703. https://doi.org/10.1021/acs.orglett.6b02865

8. Brunel, J. M. Chem. Rev. 2005, 105 (3), 857-897. https://doi.org/10.1021/cr040079g

9. Chen, Y.; Yekta, S.; Yudin, A. K. Chem. Rev. 2003, 103 (8), 3155-3211. https://doi.org/10.1021/cr020025b

10. Jones, B. A.; Balan, T.; Jolliffe, J. D.; Campbell, C. D.; Smith, M. D. Angew. Chem. Int. Ed. 2019, 58 (14), 4596-4600. https://doi.org/10.1002/anie.201814381

11. Bringmann, G.; Gulder, T.; Gulder, T. A. M.; Breuning, M. Chem. Rev. 2011, 111 (2), 563-639. https://doi.org/10.1021/cr100155e

12. Laplante, S. R.; Fader, L. D.; Fandrick, K. R.; Fandrick, D. R.; Hucke, O.; Kemper, R.; Miller, S. P. F.;

Edwards, P. J. J. Med. Chem. 2011, 54 (20), 7005-7022.

https://doi.org/10.1021/jm200584g

13. Dean, L. Med. Genet. Summ. 2012, No. Md, 1-7.

14. Bouché, L.; Christ, C. D.; Siegel, S.; Fernández-Montalván, A. E.; Holton, S. J.; Fedorov, O.; Ter Laak, A.; Sugawara, T.; Stöckigt, D.; Tallant, C.; et al. J. Med. Chem. 2017, 60 (9), 4002-4022.

https://doi.org/10.1021/acs.jmedchem.7b00306

15. Wang, J.; Zeng, W.; Li, S.; Shen, L.; Gu, Z.; Zhang, Y.; Li, J.; Chen, S.; Jia, X. ACS Med. Chem. Lett. 2017, 8 (3), 299-303. 
16. Cernak, T.; Dykstra, K. D.; Tyagarajan, S.; Vachal, P.; Krska, S. W. Chem. Soc. Rev. 2016, 45 (3), $546-576$. https://doi.org/10.1039/C5CS00628G

17. Denmark, S. E.; Burk, M. T. Proc. Natl. Acad. Sci. U. S. A. 2010, 107 (48), 20655-20660. https://doi.org/10.1073/pnas.1005296107

18. Maddox, S. M.; Nalbandian, C. J.; Smith, D. E.; Gustafson, J. L. Org. Lett. 2015, 17 (4), 1042-1045. https://doi.org/10.1021/acs.orglett.5b00186

19. Rodriguez, R. A.; Pan, C. M.; Yabe, Y.; Kawamata, Y.; Eastgate, M. D.; Baran, P. S. J. Am. Chem. Soc. 2014, 136 (19), 6908-6911.

https://doi.org/10.1021/ja5031744

20. Mendonça, G. F.; Bastos, A. R.; Boltz, M.; Louis, B.; Pale, P.; Esteves, P. M.; De Mattos, M. C. S. Appl. Catal. A Gen. 2013, 460-461, 46-51. https://doi.org/10.1016/j.apcata.2013.04.017

21. Smith, K.; Williams, D.; El-Hiti, G. A. J. Sulfur Chem. 2019, 40 (5), 529-538.

22. Gao, Y.; Lu, W.; Liu, P.; Sun, P. J. Org. Chem. 2016, 81 (6), 2482-2487. https://doi.org/10.1021/acs.joc.6b00046

23. Lv, S.; Zhou, H.; Yu, X.; Xu, Y.; Zhu, H.; Wang, M.; Liu, H.; Dai, Z.; Sun, G.; Gong, X.; et al. Commun. Chem. 2019, 2 (1), 4-13.

24. Gutmann, V. Coord. Chem. Rev. 1975, 15 (2-3), 207-237. https://doi.org/10.1016/S0010-8545(00)80274-X

25. Xiong, X.; Yeung, Y. Y. Angew. Chem. Int. Ed. 2016, 55 (52), 16101-16105. https://doi.org/10.1002/anie.201607388

26. Xiong, X.; Yeung, Y. Y. ACS Catal. 2018, 8 (5), 4033-4043. https://doi.org/10.1021/acscatal.8b00327

27. Pathak, T. P.; Miller, S. J. J. Am. Chem. Soc. 2012, 134 (14), 6120-6123. https://doi.org/10.1021/ja301566t

28. Payne, J. T.; Lewis, J. C. Synlett 2014, 25 (10), 1345-1349. https://doi.org/10.1055/s-0033-1341024

29. Payne, J. T.; Andorfer, M. C.; Lewis, J. C. Angew. Chem. Int. Ed. 2013, 52 (20), 5271-5274. https://doi.org/10.1002/anie.201300762

30. Sohtome, Y.; Tanatani, A.; Hashimoto, Y.; Nagasawa, K. Tetrahedron Lett. 2004, 45 (29), 5589-5592. https://doi.org/10.1016/i.tetlet.2004.05.137

31. Maddox, S. M.; Dinh, A. N.; Armenta, F.; Um, J.; Gustafson, J. L. Org. Lett. 2016, 18 (21), 5476-5479. https://doi.org/10.1021/acs.orglett.6b02650

32. Denmark, S. E.; Beutner, G. L. Angew. Chem. Int. Ed. 2008, 47 (9), 1560-1638. https://doi.org/10.1002/anie.200604943

33. Takahashi, S.; Suda, Y.; Nakamura, T.; Matsuoka, K.; Koshino, H. J. Org. Chem. 2017, 82 (6), 3159-3166. https://doi.org/10.1021/acs.joc.7b00147

34. Mukherjee, A. K.; Mohan, A. Die Angew. Makromol. Chem. 1987, 154 (1), 99-110. https://doi.org/10.1002/apmc.1987.051540107

35. Tunge, J. A.; Mellegaard, S. R. Org. Lett. 2004, 6 (8), 1205-1207. https://doi.org/10.1021/ol0365250

36. Ayonon, A.; Nalbandian, C.; Guillemard, L.; Gustafson, J. Tetrahedron Lett. 2017, 58 (30), $2940-2943$. https://doi.org/10.1016/i.tetlet.2017.06.042

37. Karmakar, R.; Pahari, P.; Mal, D. Chem. Rev. 2014, 114 (12), 6213-6284. https://doi.org/10.1021/cr400524q

38. Shibatomi, K.; Zhang, Y.; Yamamoto, H. Chem. - An Asian J. 2008, 3 (8-9), 1581-1584. https://doi.org/10.1002/asia.200800087

39. Marcantoni, E.; Massaccesi, M.; Petrini, M.; Bartoli, G.; Bellucci, M. C.; Bosco, M.; Sambri, L. J. Org. Chem. 
2000, 65 (15), 4553-4559.

https://doi.org/10.1021/jo000116d

40. Johannesson, P.; Lindeberg, G.; Johansson, A.; Nikiforovich, G. V.; Gogoll, A.; Synnergren, B.; Le Grèves, M.; Nyberg, F.; Karlén, A.; Hallberg, A. J. Med. Chem. 2002, 45 (9), 1767-1777.

https://doi.org/10.1021/jm011063a

41. Sader, H. S.; Johnson, D. M.; Jones, R. N. Antimicrob. Agents Chemother. 2004, 48 (1), 53-62. https://doi.org/10.1128/AAC.48.1.53-62.2004

42. Sierra, H.; Cordova, M.; Chen, C. S. J.; Rajadhyaksha, M. J. Invest. Dermatol. 2015, 135 (2), $612-615$. https://doi.org/10.1038/jid.2014.371

43. Narayan, V.; Haas, N. B. Int. J. Nephrol. Renovasc. Dis. 2016, 9, 65-72.

44. Bellesoeur, A.; Carton, E.; Alexandre, J.; Goldwasser, F.; Huillard, O. Drug Des. Devel. Ther. 2017, 11, 2801-2811.

https://doi.org/10.2147/DDDT.S109640

45. Gross-Goupil, M.; François, L.; Quivy, A.; Ravaud, A. Clin. Med. Insights Oncol. 2013, 7, $269-277$. https://doi.org/10.4137/CMO.S10594

46. Vásquez-Céspedes, S.; Ferry, A.; Candish, L.; Glorius, F. Angew. Chem. Int. Ed. 2015, 54 (19), 5772-5776. https://doi.org/10.1002/anie.201411997

47. Beletskaya, I. P.; Ananikov, V. P. Chem. Rev. 2011, 111 (3), 1596-1636.

https://doi.org/10.1021/cr100347k

48. Lee, C. F.; Liu, Y. C.; Badsara, S. S. Chem. - An Asian J. 2014, 9 (3), 706-722.

https://doi.org/10.1002/asia.201301500

49. Hostier, T.; Ferey, V.; Ricci, G.; Pardo, D. G.; Cossy, J. Chem. Commun. 2015, 51 (73), 13898-13901. https://doi.org/10.1039/C5CC05421D

50. Gillis, H. M.; Greene, L.; Thompson, A. Synlett 2009, No. 1, 112-116.

51. Hostier, T.; Ferey, V.; Ricci, G.; Gomez Pardo, D.; Cossy, J. Org. Lett. 2015, 17 (15), 3898-3901. https://doi.org/10.1021/acs.orglett.5b01889

52. Nalbandian, C. J.; Miller, E. M.; Toenjes, S. T.; Gustafson, J. L. Chem. Commun. 2017, 53 (9), $1494-1497$. https://doi.org/10.1039/C6CC09998J

53. Nalbandian, C. J.; Brown, Z. E.; Alvarez, E.; Gustafson, J. L. Org. Lett. 2018, 20 (11), 3211-3214. https://doi.org/10.1021/acs.orglett.8b01066

54. Liu, X.; Liang, Y.; Ji, J.; Luo, J.; Zhao, X. J. Am. Chem. Soc. 2018, 140 (14), 4782-4786. https://doi.org/10.1021/jacs.8b01513

55. Luo, J.; Liu, Y.; Zhao, X. Org. Lett. 2017, 19 (13), 3434-3437. https://doi.org/10.1021/acs.orglett.7b01392

56. Dong, D. Q.; Hao, S. H.; Yang, D. S.; Li, L. X.; Wang, Z. L. European J. Org. Chem. 2017, 2017 (45), 65766592.

https://doi.org/10.1002/ejoc. 201700853

57. Bissonnette, N. B.; Boyd, M. J.; May, G. D.; Giroux, S.; Nuhant, P. J. Org. Chem. 2018, 83 (18), 1093310940.

https://doi.org/10.1021/acs.joc.8b01589

58. Dinh, A. N.; Nguyen, A. D.; Aceves, E. M.; Albright, S. T.; Cedano, M. R.; Smith, D. K.; Gustafson, J. L. Synlett 2019, 30 (14), 1648-1655.

https://doi.org/10.1055/s-0039-1690107

59. Smith, D. E.; Marquez, I.; Lokensgard, M. E.; Rheingold, A. L.; Hecht, D. A.; Gustafson, J. L. Angew. Chem. Int. Ed. 2015, 54 (40), 11754-11759. https://doi.org/10.1002/anie.201506085

60. Eng, C.; Clayton, D.; Schuffenecker, I.; Lenoir, G.; Cote, G.; Gagel, R. F.; Ploos Van Amstel, H. K.; Lips, C. J. M.; Nishisho, I.; Takai, S. I.; et al. J. Am. Med. Assoc. 1996, 276 (19), 1575-1579. 
61. Mulligan, L. M.; Eng, C.; Healey, C. S.; Clayton, D.; Kwok, J. B. J.; Gardner, E.; Ponder, M. A.; Frilling, A.; Hendrik, C. E. J.; Neumann, H. P. H.; et al. Nat. Genet. 1994, 6, 70-74.

https://doi.org/10.1038/ng0194-70

62. Grieco, M.; Santoro, M.; Berlingieri, M. T.; Melillo, R. M.; Donghi, R.; Bongarzone, I.; Pierotti, M. A.; Della Ports, G.; Fusco, A.; Vecchiot, G. Cell 1990, 60 (4), 557-563.

https://doi.org/10.1016/0092-8674(90)90659-3

63. Piotrowska, Z.; Isozaki, H.; Lennerz, J. K.; Gainor, J. F.; Lennes, I. T.; Zhu, V. W.; Marcoux, N.; Banwait, M. K.; Digumarthy, S. R.; Su, W.; et al. Cancer Discov. 2018, 8 (12), 1529-1539. https://doi.org/10.1158/2159-8290.CD-18-1022

64. Boulay, A.; Breuleux, M.; Stephan, C.; Fux, C.; Brisken, C.; Fiche, M.; Wartmann, M.; Stumm, M.; Lane, H. A.; Hynes, N. E. Cancer Res. 2008, 68 (10), 3743-3751.

https://doi.org/10.1158/0008-5472.CAN-07-5100

65. Chen, Z.; Zhao, Y.; Yu, Y.; Pang, J. C.; Woodfield, S. E.; Tao, L.; Guan, S.; Zhang, H.; Bieerkehazhi, S.; Shi, Y.; et al. Oncotarget 2017, 8 (61), 104090-104103.

https://doi.org/10.18632/oncotarget.22011

66. Lambertz, I.; Kumps, C.; Claeys, S.; Lindner, S.; Beckers, A.; Janssens, E.; Carter, D. R.; Cazes, A.; Cheung, B. B.; De Mariano, M.; et al. Clin. Cancer Res. 2015, 21 (14), 3327-3339.

https://doi.org/10.1158/1078-0432.CCR-14-2024

67. Toenjes, S. T.; Garcia, V.; Maddox, S. M.; Dawson, G. A.; Ortiz, M. A.; Piedrafita, F. J.; Gustafson, J. L. ACS Chem. Biol. 2019, 14, 1930-1939.

https://doi.org/10.1021/acschembio.9b00407

68. Leung, C. S.; Leung, S. S. F.; Tirado-Rives, J.; Jorgensen, W. L. J. Med. Chem. 2012, 55 (9), 4489-4500. https://doi.org/10.1021/jm3003697

69. Miyaji, R.; Asano, K.; Matsubara, S. J. Am. Chem. Soc. 2015, 137 (21), 6766-6769. https://doi.org/10.1021/jacs.5b04151

70. Costil, R.; Dale, H. J. A.; Fey, N.; Whitcombe, G.; Matlock, J. V.; Clayden, J. Angew. Chem. Int. Ed. 2017,56 (41), 12533-12537.

https://doi.org/10.1002/anie.201706341

71. Fugard, A. J.; Lahdenperä, A. S. K.; Tan, J. S. J.; Mekareeya, A.; Paton, R. S.; Smith, M. D. Angew. Chem. Int. Ed. 2019, 58 (9), 2795-2798.

https://doi.org/10.1002/anie.201814362

72. Diener, M. E.; Metrano, A. J.; Kusano, S.; Miller, S. J. J. Am. Chem. Soc. 2015, 137 (38), 12369-12377. https://doi.org/10.1021/jacs.5b07726

73. Boström, J.; Brown, D. G.; Young, R. J.; Keserü, G. M. Nat. Rev. Drug Discov. 2018, 17, 709-727. https://doi.org/10.1038/nrd.2018.116

74. Armstrong, R. J.; Smith, M. D. Angew. Chem. Int. Ed. 2014, 53 (47), 12822-12826.

https://doi.org/10.1002/anie.201408205

75. Cardenas, M. M.; Toenjes, S. T.; Nalbandian, C. J.; Gustafson, J. L. Org. Lett. 2018, 20 (7), $2037-2041$. https://doi.org/10.1021/acs.orglett.8b00579

76. Organ, M. G.; Abdel-Hadi, M.; Avola, S.; Dubovyk, I.; Hadei, N.; Kantchev, E. A. B.; O’Brien, C. J.; Sayah, M.; Valente, C. Chem. - A Eur. J. 2008, 14 (8), 2443-2452.

https://doi.org/10.1002/chem.200701621

77. Chen, Y. H.; Qi, L. W.; Fang, F.; Tan, B. Angew. Chem. Int. Ed. 2017, 56 (51), 16308-16312. https://doi.org/10.1002/anie.201710537

78. Chen, Y. H.; Cheng, D. J.; Zhang, J.; Wang, Y.; Liu, X. Y.; Tan, B. J. Am. Chem. Soc. 2015, 137 (48), 1506215065.

https://doi.org/10.1021/jacs.5b10152

79. Maddox, S. M.; Dawson, G. A.; Rochester, N. C.; Ayonon, A. B.; Moore, C. E.; Rheingold, A. L.; Gustafson, 
J. L. ACS Catal. 2018, 8 (6), 5443-5447.

https://doi.org/10.1021/acscatal.8b00906

80. Konkol, L. C.; Guo, F.; Sarjeant, A. A.; Thomson, R. J. Angew. Chem. Int. Ed. 2011, 50 (42), 9931-9934. https://doi.org/10.1002/anie.201104726

81. Wu, P.; Nielsen, T. E.; Clausen, M. H. Trends Pharmacol. Sci. 2015, 36 (7), 422-439. https://doi.org/10.1016/j.tips.2015.04.005

82. Mologni, L.; Redaelli, S.; Morandi, A.; Plaza-Menacho, I.; Gambacorti-Passerini, C. Mol. Cell. Endocrinol. 2013, 377 (1-2), 1-6.

https://doi.org/10.1016/j.mce.2013.06.025

83. Boger, D. L.; Castle, S. L.; Miyazaki, S.; Wu, J. H.; Beresis, R. T.; Loiseleur, O. J. Org. Chem. 1999, 64 (1), 70-80.

https://doi.org/10.1021/jo980880o

84. Knox, J. R.; Pratt, R. F. Antimicrob. Agents Chemother. 1990, 34 (7), 1342-1347. https://doi.org/10.1128/AAC.34.7.1342

85. Yuan, B.; Page, A.; Worrall, C. P.; Escalettes, F.; Willies, S. C.; McDouall, J. J. W.; Turner, N. J.; Clayden, J. Angew. Chem. Int. Ed. 2010, 49 (39), 7010-7013.

https://doi.org/10.1002/anie.201002580

86. Dinh, A.; Noorbehesht, R.; Toenjes, S.; Jackson, A.; Saputra, M.; Maddox, S.; Gustafson, J. Synlett 2018, 16.

87. Sarkar, R.; Mukherjee, S. Org. Lett. 2016, 18 (23), 6160-6163.

https://doi.org/10.1021/acs.orglett.6b03168

88. Manna, M. S.; Mukherjee, S. J. Am. Chem. Soc. 2015, 137 (1), 130-133.

https://doi.org/10.1021/ja5117556

89. Vaidya, S. D.; Toenjes, S. T.; Yamamoto, N.; Maddox, S. M.; Gustafson, J. L. J. Am. Chem. Soc. 2020, 142 (5), 2198-2203.

https://doi.org/10.1021/jacs.9b12994

90. Costil, R.; Sterling, A.; Duarte, F.; Clayden, J. Atropisomerism in Diarylamines: Angew. Chem. Int. Ed. 2020, 59, 2-11.

https://doi.org/10.1002/anie.202007595

91. Kawabata, T.; Jiang, C.; Hayashi, K.; Tsubaki, K.; Yoshimura, T.; Majumdar, S.; Sasamori, T.; Tokitoh, N. J. Am. Chem. Soc. 2009, 131 (1), 54-55. https://doi.org/10.1021/ja808213r

\section{Authors' Biographies}

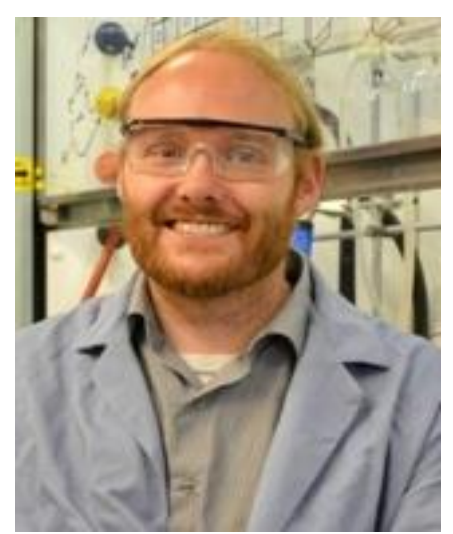

Prof. Jeffrey L. Gustafson obtained his B.Sc. in chemistry in 2005 from San Diego State University (SDSU). He then moved to Yale University where he worked with Professor Scott Miller on the application of low 
molecular weight peptides as catalysts for the functionalization of phenols. He obtained his Ph.D. in 2011, then stayed at Yale for his postdoctoral studies with Professor Craig Crews where he worked on the first generation of small-molecule PROTACs. In 2013 he came back to SDSU where he started a research program revolving around the applications of atropisomerism to drug discovery.

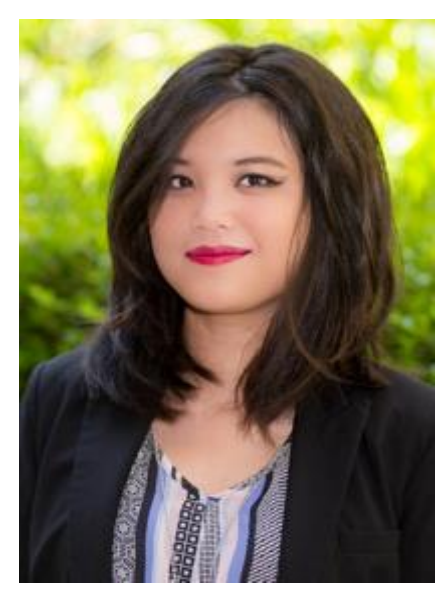

Mariel Manaloto Cardenas obtained her B.Sc. in Chemistry in 2014 from the University of California at San Diego (UCSD). At present she is a Joint Doctoral Ph.D. candidate at SDSU and UCSD under the supervision of Professor Jeffrey L. Gustafson. She is currently developing various atroposelective methodologies to access pharmaceutically relevant $N$-heterocyclic scaffolds. ORCID: 0000-0001-5557-4616

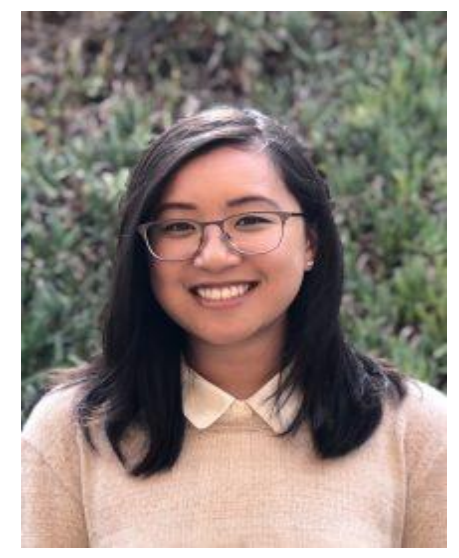

Ashley Dang-Nguyen was born in San Jose, California. She obtained her B.S. in Chemistry in 2017 from San Jose State University. In 2018 she joined the Joint Doctoral Ph.D. program at SDSU and UCSD. Her research focuses on the development of Lewis base catalyst controlled aromatic functionalization. 


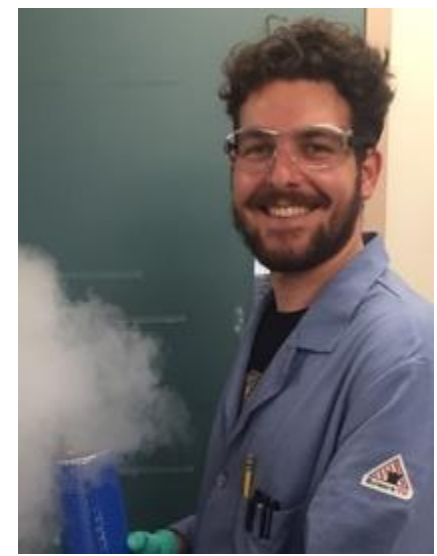

Zachary E. Brown received his B.S. Chemistry at CSU Channel Islands. He is currently a Joint Doctoral Ph.D. student at SDSU and UCSD under mentorship from Professor Jeffrey Gustafson. Zach's research is currently focused on Lewis base catalyzed sulfenylations and its applications in chemical biology.

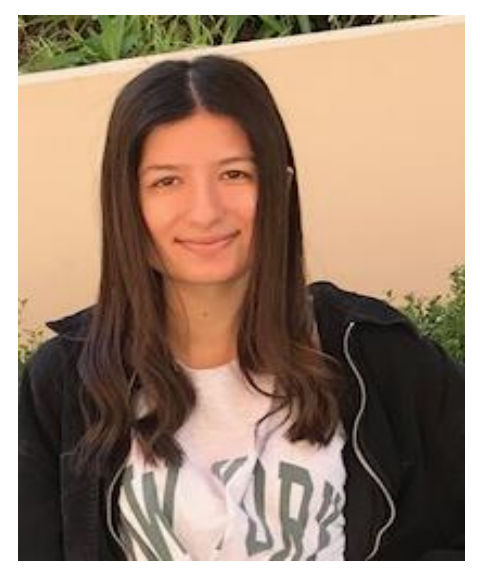

Beeta S. Heydari obtained her B.Sc. degree in Biochemistry with departmental honors from the University of Washington, Seattle in 2019. Currently, she is a second-year graduate student at San Diego State University under the supervision of Professor Jeffrey L. Gustafson. She is currently working on assessing the effects of intramolecular hydrogen bonding towards the stereochemical stability of diaryl amines, with the goal of developing selective and potent kinase inhibitors involved in cancer.

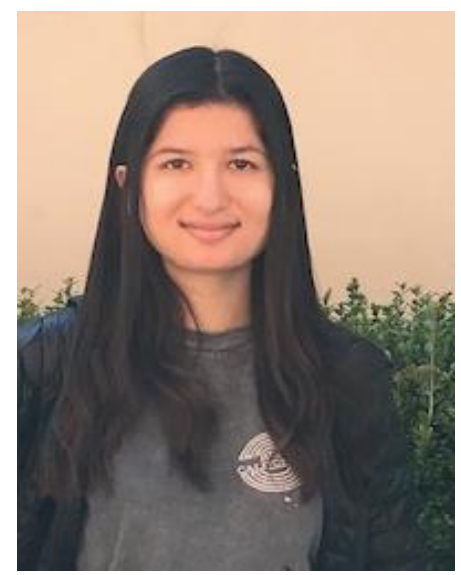

Bahar S. Heydari obtained her B.S.C in Biochemistry with departmental honors in from the University of Washington, Seattle in 2019. She is currently a second-year graduate student at San Diego State University 
under the supervision of Professor Jeffrey L. Gustafson. She is currently working on developing dihedral angle tuned PPYs to improve kinase inhibitor selectivity involved in cancer.

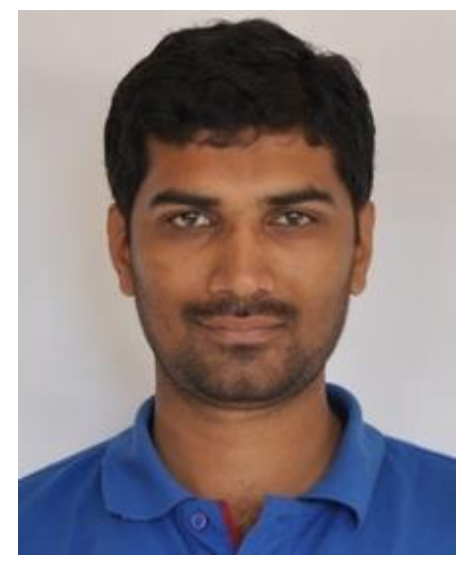

Dr. Sagar D. Vaidya obtained his B.Sc. (Chemistry Honors) from Adv. M. N. Deshmukh College, Rajur (Akole, Maharshtra) in 2008. He obtained his M.Sc. In 2010 from the Fergusson College Pune. Immediately afterward, he started his Ph. D. at National Chemical Laboratory Pune, under the supervision of Professor Narshinha P. Argade, where he worked on the total synthesis of quinazolinone alkaloids. In August 2016 Sagar joined Professor Christopher Switzer's group for postdoctoral research in University of California Riverside, where he worked on non-natural deoxyribonucleic acids. In November 2017, he moved to San Diego State University in the group of Professor Jeffrey Gustafson. He is currently working on development of atroposelective late stage functionalization of biaryl anilines and development of selective and potent EGFR kinase inhibitors. 